\title{
Model of Crisis Resilient Organizations
}

\author{
Dr. Hassan CHAGAR
}

\author{
Researcher - ISCAE Group - Morocco
}

\begin{abstract}
This communication offers a contribution to rethinking organizational models. Its objective is to propose the determinants of resilient organizations in the face of crises generated by unforeseen risks with high impact, called black swans. It is a metaresearch that takes advantage of the results of 11 studies conducted and concluded in the midst of the COVID 19 crisis. The central question that has been the common thread of this meta-research is "What new managerial model of resilient organizations? To answer this question, she exploits the quintessential state of the art mobilized by this research and its results. This research adopted a rather qualitative analysis approach; the discussion of their results made it possible to bring out the determinants of the model of resilient organizations structuring three levers: valuing the raison d'être, organizational efficiency and ecosystem leadership. These determinants are the first lever: the alignment of strategies with social and societal imperatives, the foundation of the corporate culture on multicultural values and the integration of risks in the management of projects and the business model. For the second component, these determinants are: employee engagement, collective intelligence, organizational agility and business architecture. For the last component, these determinants are: the digital transformation of the customer journey, the improvement of the customer experience by creating the wow effect, the extension of markets via a growth strategy based on exports and ecosystem management as the basis of strategic management.
\end{abstract}

KEYWORDS: Resilient organization, Valorization of purpose, Organizational efficiency, Ecosystem leadership

\section{INTRODUCTION}

This paper proposes a contribution to rethinking organizational models. It aims to propose the determinants of resilient organizations in the face of crises generated by unforeseen high-impact risks, called black swans.

Classical management theories advocating long-term strategies, future predictions, business planning, organizational reliability, change management and capitalization on experiences are challenged and call for realtime and large-scale management, strategic thinking, business model implementation, organizational flexibility, constant transformation, and constant renewal of skills.

The knowledge that articulates this paper is a contribution to approach the new concepts of post-covid management. It is based on the results of 11 research studies conducted and concluded in the midst of the COVID 19 crisis, as part of the professional theses of the AMBA accredited Executive MBA program of the ISCAE Group.

Indeed, the results of his research corroborate the proposed model, which is structured around three pillars: the reinforcement of the raison d'être, organizational efficiency and eco-systemic leadership.

To illustrate the value of the raison d'être that drives resilient organizations, the following research findings, which are relevant to several types of companies, have been mobilized.
- Which Intercultural Management for Multinationals? The case of KSB Monde Group (a German multinational in the field of pumps)?

- Strategies at the base of the economic pyramid: Cost effective approaches to fight against poverty and social exclusion. Case of Al Omrane Morocco (Public organization in charge of social housing development).

- Risk management of World Bank projects. Case of social projects in Morocco financed by the World Bank.

- These professional theses suggest the following research questions:

- Which intercultural management for performance in a global context?

- Which cost-effective managerial approaches to fight against poverty and social exclusion?

- Which risk management system for successful social projects?

- What ecosystem for a successful crisis resolution regime?

The hypotheses that this research proposes as answers to these questions assume, first, that corporate culture would benefit from evolving towards an intercultural management that integrates diversified values and unifying principles of stakeholders. Then, they assume that it would be relevant to re-examine the vocation of organizations in order to orient it towards societal responsibility and socio-economic impacts. 


\section{"Model of Crisis Resilient Organizations"}

Finally, they assume that risk management would be a lever for the success of projects driven by social goals.

To illustrate the importance of organizational efficiency in strengthening resilience, the following research findings, which are relevant to several sectors of activity, have been mobilized:

- Neuro-management: A lever for strengthening employee engagement. Case study of the retail banking department of "Société Générale" Africain Business Services (banking sector)

- Collective intelligence at the service of company performance. Case of "Eaux Minérales de Oulmes Maroc" (An industrial company in the field of water bottling and marketing).

- Agility as a growth lever in the mining industry of aggregate production (Case of a Moroccan SME).

- Enterprise architecture and agility as a strategic asset of the company. Case of an insurance company in Morocco in times of crisis COVID 19.

- These professional theses suggest the following research questions:

- What lever to strengthen employee engagement?

- What mode of collaboration to serve the performance of companies?

- What mode of organization animation to support growth?

- Which enterprise architecture for the implementation of business strategies.

The hypotheses that this research proposes as answers to these questions assume, first, that employee commitment is important for sustainable performance, drawing on knowledge of motivation from neuroscience. Then, they assume that collective intelligence would be a lever for managing and adapting to the complexity of an increasingly VICA environment. Finally, they assume that agility would be a lever for organizational efficiency and effectiveness, particularly through the digitalization of the value chain.

To illustrate the value of ecosystemic leadership that strengthens the execution of resilient organizational strategies in an uncertain context, the following research findings, which are relevant to both public and private organizations, have been mobilized:

- Digital transformation of the customer journey. Hyundai Morocco case study (car dealership)

- Which approach to improve the customer experience: Case of ONCF Morocco (public institution in charge of managing railway infrastructures and related services)?

- Which export strategy for the growth of Moroccan SMEs; Case of FIABEL SARL (A Moroccan SME active in the field of products and services related to electricity)

- What ecosystem for an efficient financial crisis resolution regime in Morocco?
These professional theses suggest the following research questions:

- Which digital transformation to enrich the customer journey?

- Which approach to improve the customer experience?

- What export strategy for SME growth?

- Which ecosystem for an efficient crisis resolution regime?

The hypotheses that this research proposes as answers to these questions assume, first, that the place of the customer would be decisive in the ecosystem of resilient organizations that would take care of transforming the customer relationship to offer pathways and experiences enhanced by the digital footprint improving customer satisfaction and commitment. Then, they assume that the enlightened strategic direction would be to expand the commercial surface and penetrate, through export, new markets to duplicate successful business models at the local level to other regions and compensate for local market saturation. Finally, assume that ecosystem leadership would be a true strategic capability, especially in crisis situations, to share risks, strengthen environmental knowledge and build common resilience solutions.

The central issue that unites all these research projects can be expressed in terms of

"What new managerial model for resilient organizations? These studies all follow a scientific reasoning that starts from a context that proposes research questions and leads to a problematic. Then they start from a set of hypotheses as supposed answers to these research questions to determine the research objectives and the approach and methodology to achieve them.

Most of the approaches adopted are qualitative in order to encourage recursive, semi-directive exchanges that enrich the questioning that the validation of research hypotheses generates.

Some of the above-mentioned research has already been published. Indeed, the research on "Which ecosystem for an efficient financial crisis resolution regime in Morocco" and the research on "Strategies at the base of the economic pyramid: Cost-effective approaches to fight against poverty and social exclusion" have contributed, via two chapters, to the production of a co-authored book published by the French journal of economics and management (April 2020 Session). The quintessence of the conclusions of this research, which can be articulated around the three proposed pillars of a resilient organizational model: the consolidation of the raison d'être, the organizational efficiency and the eco-systemic leadership, can be erected to a synthesis of a meta research and the proposed model can still be a base for other researches that try to identify the new management referentials in the era of the VICA and the black swans

To support the information given in the introduction, this article will begin by sharing the quintessence of the concepts and models mobilized by the above-mentioned research. It 


\section{"Model of Crisis Resilient Organizations"}

will then present a summary of the empirical approaches they have taken. Before concluding, it will propose the salient results of this research before discussing them in order to validate the aforementioned hypotheses and corroborate the determinants of the resilient organization model.

\section{Lessons from the state of the art.}

Three fields of knowledge inform the theoretical underpinning of the resilience model sought, namely knowledge of valuing purpose, knowledge informing organizational efficiency and knowledge guiding ecosystemic leadership.

\subsection{The value of purpose.}

The raison d'être must be constantly revisited, according to a constant strategic thinking, especially in a VICA context of black swans, to reposition in a global context the strategy, the corporate culture and the risk management.
Integrating the social and societal dimension into the strategy is essential to gain resilience. Indeed, it was one of the determining factors in the response plans of nations to the Covid pandemic and can prove, as the lessons learned from the BoP approaches presented below show, not only necessary but also profitable in the long term. This profitability can only be effective if it is anchored in a managerial frame of reference that draws its motivations from intercultural management and that makes risk management a lever for performance management.

\subsubsection{Strategy at the base of the pyramid (BoP).}

The new BoP approaches, which invert the pyramid and broaden the concern for entrepreneurial action to all the niches of the client ecosystem, to include those left behind, are, as shown in the following diagram 1, a new form of management, combining wealth creation and social development.

\begin{tabular}{|c|c|c|}
\hline & $\begin{array}{l}\text { Market capture } \\
\text { BoP } 1.0 \text { approach }\end{array}$ & $\begin{array}{l}\text { Market building } \\
\text { BoP } 2.0 \text { approach }\end{array}$ \\
\hline $\begin{array}{l}\text { Initial } \\
\text { situation }\end{array}$ & Existing solvent demand & No market \\
\hline Goals & Market penetration & Creation of a market \\
\hline $\begin{array}{l}\text { Economic } \\
\text { model }\end{array}$ & $\begin{array}{l}\text { - Poor perceived as potential } \\
\text { consumers } \\
\text { - Limited adaptation of the } \\
\text { economic model } \\
\text { - Finding a model that can be } \\
\text { easily replicated }\end{array}$ & $\begin{array}{l}\text { - Poor perceived as consumers and stakeholders } \\
\text { - Partnership with NGOs or social enterprises aiming to } \\
\text { combine skills and develop new resources for the } \\
\text { company } \\
\text { - Local experimentation }\end{array}$ \\
\hline Management & $\begin{array}{l}\text { - Results evaluated according to } \\
\text { the standard performance } \\
\text { measurement criteria for the } \\
\text { company. }\end{array}$ & $\begin{array}{l}\text { - Results evaluated according to criteria specific to the } \\
\text { project and valuing learning. }\end{array}$ \\
\hline Funding & $\begin{array}{l}\text { Mainly marketing costs, borne by } \\
\text { the company. }\end{array}$ & $\begin{array}{l}\text { - Financing the implementation of the ecosystem. } \\
\text { - Cost of social marketing. } \\
\text { - Investment in the capital of the structure, according to } \\
\text { innovative methods. }\end{array}$ \\
\hline
\end{tabular}

Figure 1: Evolution of BoP approaches (Perrot, 2010)

This form, which has been corroborated by the Covid pandemic experience, takes a disruptive look at the quality of the people to be served to perceive their service as a business opportunity and not a philanthropic or public relations action. This disruptive view broadens the scope of intervention to capture create new market niches. (Perrot, 2011)

The BoP approach invites us to review strategic management (Martinet and Payaud, 2010) to align strategic intent with this new vision, to adapt its client target, to reconfigure its supply system, to reconquer the appropriate ecosystem and to redefine the necessary strategic competencies. This strategic revision, as illustrated in the following diagram 2 , allows the company to approach the market according to all its segments and to be innovative in order to provide frugal and holistic answers to the needs of those segments that seem economically unattractive according to classical economic thinking. 


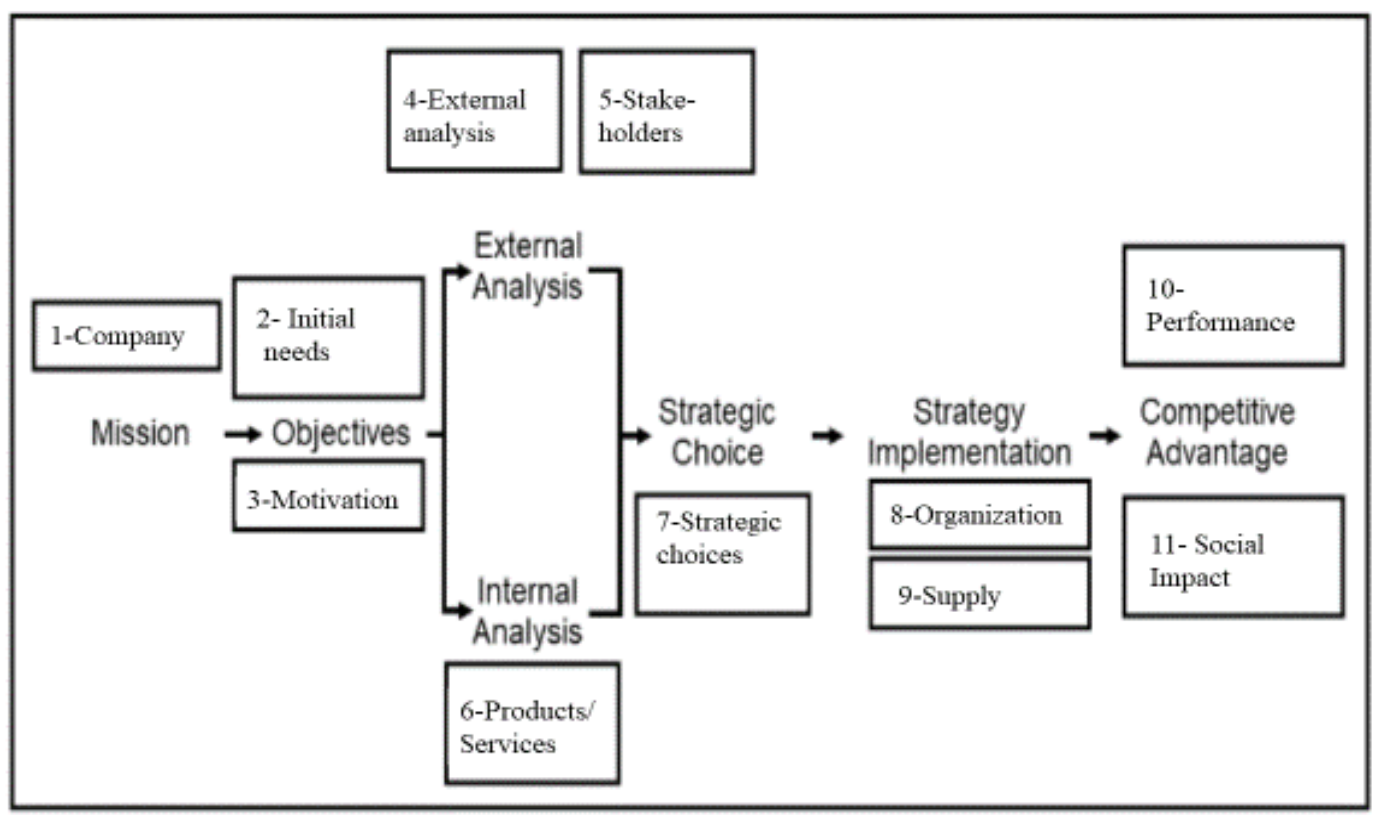

Figure 2: Application of the strategic management process to BoP (Schrader, Freimann, and Seuring, 2012).

The classic 4Ps mix is then supplanted by the 4As (Anderson $\&$ Billou, 2007), which promote a service offer informed by new values: Acceptability, Availability, Affordability, Awareness.

Its successful deployment requires (Gollakota, Gupta and Bork, 2010), on the one hand, an optimization of the efficiency of the value chain and, on the other hand, a creation of value by translating the needs of the social strata addressed into sources of ecosystemic innovation.

\subsubsection{Intercultural management.}

The new challenges of managerial performance are becoming global and the reference territory of managerial action is becoming worldwide. Competencies are becoming de facto international, heralding the rise of cultural diversity within companies. This calls for intercultural management to establish an integrated cultural base that consolidates shared values and recognizes the cultural singularities of employees to make them a source of enrichment for the organizational model.

Intercultural management is expressed, as shown in the following diagram, according to the positioning of the management style in relation to seven cultural dimensions (Trompenaars \& Hampden-Turner, 2010):

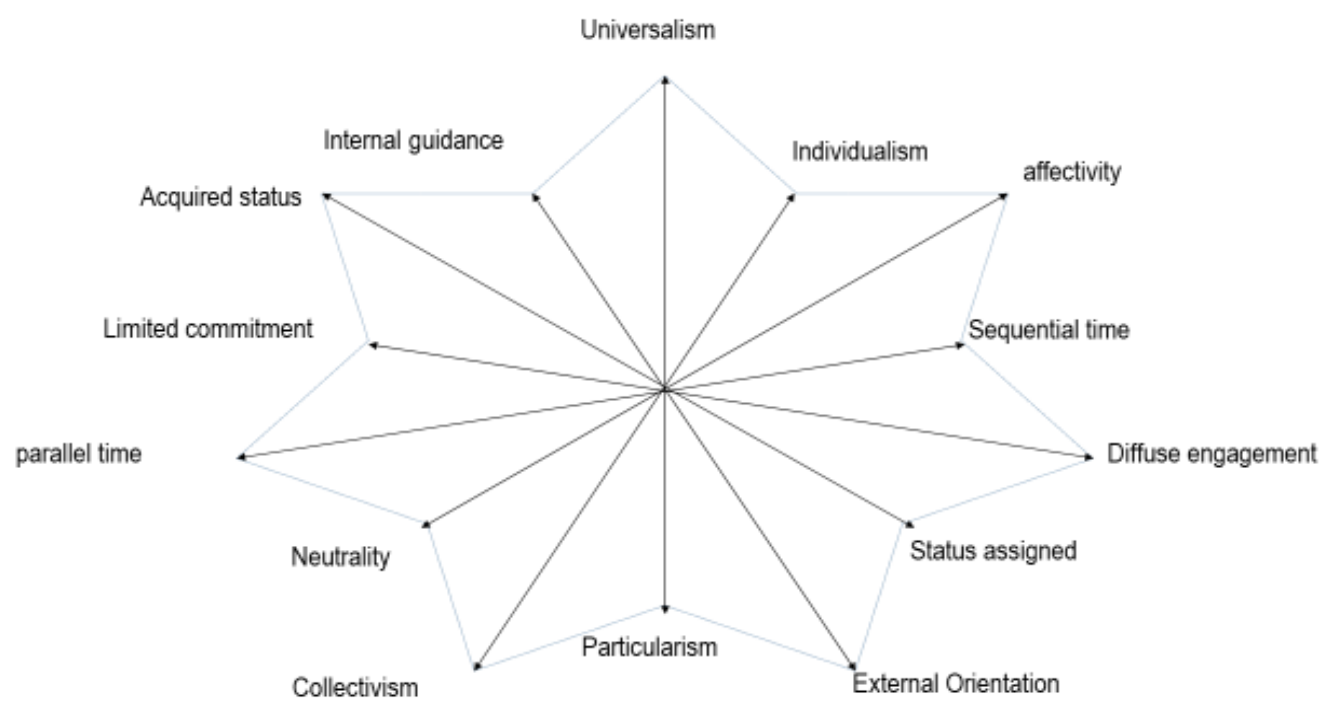

Figure 3: Adapted from The Seven Cultural Dimensions (Trompenaars \& Hampden-Turner, 2010)

The performance of intercultural management depends on the right mix of these seven criteria and requires an effort of acculturation of the employees to align their behavior with the desired balance between universal or particular perception of 
values, individual or collective contribution, neutrality of relations or affective interaction, the constant commitment or the diffuse involvement, the attribution defined by the status attributed or the status acquired thanks to the contributions, the sequential planning of the activities or the concomitant management of several activities and finally the external orientation or the internal orientation of the managerial decisions and actions.

The diversity of individuals mobilized within the company makes the management of these balances difficult. The concern for acculturation must then animate the intercultural management style to negotiate the conciliation between the corporate culture and the culture inherited by the employees according to their life experiences. This translates (Berry, 1992) into four situations depending on the level of adoption of the corporate culture and the level of identification with its cultural heritage:

- Separation: when the employee remains rooted in his or her cultural heritage and does not show a predisposition to adopt the corporate culture.

- Marginalization: when the employee identifies neither with the corporate culture nor with his/her cultural heritage.

- Integration: when the employee opens up to the corporate culture without questioning his/her cultural heritage.

- Assimilation: when the employee frees himself from his cultural heritage and finds himself in the corporate culture.

The acculturation process, which aims at the full adoption of the corporate culture, goes through phases of conflict and crisis after the pre-contact and contact phases before reaching the ultimate phase of adaptation. This process acts on the behavior of employees to escape the situation of marginalization and evolve towards situations of integration and assimilation.

The acculturation process involves a confrontation between the corporate culture and the cultural heritage of the employees in order to seek coherence between them. From this confrontation can arise three identity strategies (Camilleri, 2016):

- A simple coherence where the cultural conflict between the corporate culture and the cultural heritage of the employees results in the suppression of one to the detriment of the other.

- A complex coherence where the cultural conflict between the corporate culture and the cultural heritage of the employees generates new versions of these cultures suggesting new modalities.

- A coherence by moderation where the cultural conflict between the corporate culture and the cultural heritage of the employees is treated as a normal managerial fact that must be negotiated in order not to hinder the commitment of the employees.

\subsubsection{Risk management}

In order to deal with the challenges of positive social, societal and ecological impact and the constraints they create, companies must revise their risk management cultures and skills. Contrary to the traditional approach that advocates a culture of compliance and a focus on the most likely risks, the new risk management culture urges decision-makers to integrate risks as an inductor of business model disruption and a foundation for innovative strategies, and to reorient risk management towards the least likely risks, the so-called black swans, which, if they occur, can cause great damage.

Feedback from companies can also be capitalized on the risk management component to allow for a gain in maturity.

Risk management competence is assessed according to (Hopkinson, 2011): the level of consideration given to stakeholders, the performance of risk identification, the relevance of risk analysis, the responses to the risks incurred, the management of projects with regard to these risks and the risk management culture that results from these practices.

As shown in the following diagram, four levels of risk management maturity are distinguished, depending on the level of awareness, the quality of development and deployment of the risk management system, and the final performance of risk management.

\begin{tabular}{|l|l|l|l|l|l|}
\hline Maturity level & $\begin{array}{l}\text { Awareness of risk } \\
\text { management }\end{array}$ & $\begin{array}{l}\text { Development of risk } \\
\text { management }\end{array}$ & $\begin{array}{l}\text { Deployment of risk } \\
\text { management }\end{array}$ & $\begin{array}{l}\text { Performance of risk } \\
\text { management }\end{array}$ \\
\hline 1- Naif & Insufficient & Unstructured & Faulty app & Lack of added value \\
\hline 2- Novice & $\begin{array}{l}\text { Recognized } \\
\text { contributions }\end{array}$ & Lack of formalized process & $\begin{array}{l}\text { Impoverished by } \\
\text { inadequate design }\end{array}$ & Few benefits realized \\
\hline 3- Normalized & Effective & $\begin{array}{l}\text { Process formalized and } \\
\text { integrated into the value chain }\end{array}$ & $\begin{array}{l}\text { Systematic } \\
\text { implementation in projects }\end{array}$ & $\begin{array}{l}\text { Benefits not achieved in } \\
\text { all projects }\end{array}$ \\
\hline 3- Natural & Full & $\begin{array}{l}\text { Responsive and proactive } \\
\text { design }\end{array}$ & $\begin{array}{l}\text { Taken into account in the } \\
\text { animation of the value } \\
\text { chain and relations with } \\
\text { stakeholders }\end{array}$ & $\begin{array}{l}\text { Systematic management } \\
\text { of uncertainties for global } \\
\text { and sustainable } \\
\text { performance }\end{array}$ \\
\hline
\end{tabular}

Figure 4: Adapted from the Hopkinson Risk Maturity Model (Hpkinson, 2011) 
In order to gain in maturity and to reinforce the four determinants of this maturity, as presented in the previous diagram, risk management benefits from adopting the formalisms of the COSO model of internal control. In its version 2, it proposes a more global and transverse model, and addresses three dimensions:

- The internal control process, which starts with the definition of objectives and goes through the phases of identifying events, assessing risks, responding to this assessment, controlling activities and sharing information and communications with stakeholders, and ends with the monitoring of performance.

- The organization through its different levels: business unit, division, entities and subsidiarity (project team and individuals).

- The management process: strategy, operations, reporting and validation, compliance of risk management with the management framework.

\subsection{The importance of organizational efficiency.}

Organizational efficiency is the challenge of organizational effectiveness and a lever for maximizing margins and profits of companies. It calls for the optimization of management systems and managerial efforts. This optimization is facilitated by an understanding of the determinants of human behavior, which neuroscience seeks to shed light on, organizational learning capacity, which collective intelligence maintains, transverse and synergistic operation, which the agility culture proposes, and the integration of digital technology as the basis of the architecture of business model values, which enterprise architecture approaches allow.

\subsubsection{Neuro-management}

The efficiency of organizations depends on the commitment of employees and stakeholders. To meet this requirement, organizations need to identify the parameters of the human brain that drive motivation and those that drive dissatisfaction. Indeed, the appreciation, decision making and reaction systems of individuals are influenced by two systems that characterize the human brain (Kahneman, 2012): "System 1" which appeals to the left hemisphere and refers to the spontaneity of individuals, apriori and irrationality, and "System 2" which appeals to the right hemisphere and refers to the hindsight of individuals, analyses and rationality.

To stimulate the use of both systems in a combined and complementary way allows us to have infirmations and to adopt reasoning that favors the good appreciation of reality and the good behavior of individuals.

Neuroscience teaches us that this behavior is the result of the expression of six neurotransmitters according to the flow of information active in the human brain. It also teaches us that, given the roles of these neurotransmitters, the individual is predisposed to be motivated. Indeed, the reward circuit is triggered by four neurotransmitters:

- Endorphin: this is the calming hormone generated by humor and pleasant atmospheres,

- Serotonin: it is the hormone of happiness generated by the awareness of the contribution,

- Dopamine: is the motivating hormone generated by the feeling of recognition and celebration,

- Oxytocin: is the attachment hormone generated by the culture of trust and connection with others.

To gain organizational efficiency, the management style that drives relationships with employees must favor the inducers of these neurotransmitters and muzzle the action of the other two neurotransmitters that characterize the threat circuit and that can reinforce dissatisfaction and fear.

Moreover, oxytocin, the marker of a culture of trust, can be the synthesis of other positive neurotransmitters and, as shown in the diagram below, it allows a management style that supports a culture of trust to generate a strengthening of commitment and, de facto, a gain in performance.

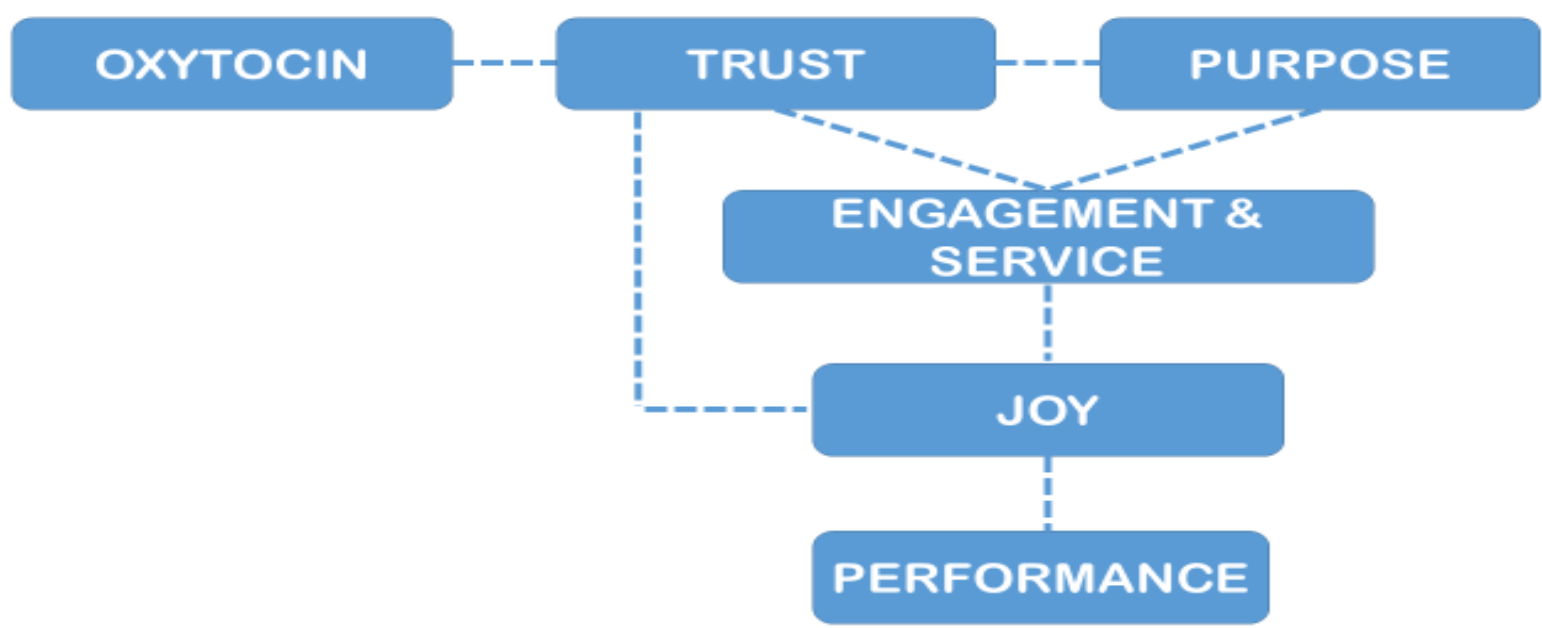

Figure 5: How does oxytocin improve the work environment? (Zak, 2017) 


\section{"Model of Crisis Resilient Organizations"}

The SCARF model (Rock, 2008) proposes the criteria that influence the culture of trust and highlight the management style of rewards and sanctions:

- Status (Status for the $\mathrm{S}$ in the SCARF model): determines the value of assigned roles,

- Certainty ( $\mathrm{C}$ in the SCARF model): defines the correct appropriation of the attributions that these roles suggest,

- Autonomy (A in the SCARF model) which questions the degree of autonomy of the employees,

- Relationships (Relatedness for the $\mathrm{R}$ of the SCARF model) which represents the relational framework and belonging of the collaborations,

- Fairness (F in the SCARF model) which refers to the fair treatment of collaborators.

\subsubsection{Collective intelligence}

The ability to understand the professional context and to manage its complexity and uncertainty depends on the quality of the data and information available. Relevant information promotes good decision making and serves the experiences of individuals.

The capitalization of feedback in organizations is a source of collective intelligence which "refers to the intelligence realized at different collective levels of the organization, if not in the whole organization; it is not the sum of individual intelligences. Collective intelligence is the intelligence of work groups. (Levy, 1997). Collective intelligence is "all the intellectual capacities (of understanding, reflection, decision and action) of a work group resulting from the interaction between its members and implemented to face a complex situation." (Zaïbet and Greselle,2007). It is a "tool to develop responsibility, creativity, adaptability of an organization and ensure the implementation of decisions by reducing resistance to change and creating a positive emulation" (Zara, 2016 ).

It is characterized by two systemic dimensions (Zaïbet and Greselle, 2007):

- A cognitive dimension that represents the professional experience and results from the sharing of factual reflection, the understanding of reality to reach a collective decision translating the common objective that guides the collective. This dimension translates the collective understanding according to the sharing of language, understanding, representation, and elaboration actions. It presents the collective reflection according to the theoretical knowledge, the actionable knowledge and the know-how.

- A relational dimension that represents the relational experience according to the collective action. This relational experience is apprehended, on the one hand, according to the levels of interdependence, interaction and co-activity that characterize the collaboration of the actors, and on the other hand, according to the behavior, the cohesion of the teams and the potential conflicts as well as the degree of autonomy and trust.

- Collective intelligence calls for two logics that benefit from being positively confronted in order to move organizations towards collective intelligence:

- The vertical "System" logic of order and institution that fuels the execution engine and legitimizes the principles of discipline, authority and hierarchy and the command and control systems. It is driven by the concern of directing the actors to make decisions according to the objectives set and the expected results.

- Transversal "actor" logic of chaos and individuality that feeds the design engine and guides decision making, transversality and co-construction and maintains freedom and knowledge. It promotes good decision making through listening and thinking skills in a context of sharing.

\subsubsection{Agility}

The VICA environment that characterizes the evolutionary context of organizations alters the effectiveness and therefore the efficiency of value chains. The search for effectiveness requires several iterations of the processes to approach the adequacy of the achievements with the expectations. This iteration time explains the potential loss of efficiency in organizations.

To meet the challenge of efficient effectiveness, organizational agility may be the solution. This concept, which has proven its efficiency in the development of digital solutions, can be replicated in other development and service projects, especially in a context of uncertainty and constant change of desiderata.

Agility offers, in fact, "the possibility of reacting quickly to change, but also of acting and mastering it, thanks to significant capacities for anticipation, innovation and learning" (Shafer, 1997).

Agile experiences are conducive to continuous improvement and innovation. They decline the organization according to a processual and transverse logic where the classic office organization gives way to a liberated organization based on the collaboration of three types of teams (Darrell, Sutherland and Noble, 2018): customer experience teams, business process teams and technology system teams.

Agile experiences leverage collective intelligence and data that tracks feedback internal and external to the organization to make the right options and build the right decisions. They make experimentation and virtual testing a source of learning and process optimization. They are enriched by standardization and automation efforts allowing for more reproducibility and predictability of results. The resulting operations are integrated at the value chain level and centrally driven.

Agile experiences, as shown in the following diagram, translate agile practices in relation to change management, human capital development, collaboration and value creation. 
They are based, on the one hand, on the sharing of vision, values and performance indicators and, on the other hand, on adaptive resources, namely structure and organization, processes, human resources and technology. Capitalizing on these agile practices strengthens the ability of agile organizations to watch and listen, to learn and to innovate, and to respond quickly to the needs of their customers and stakeholders.

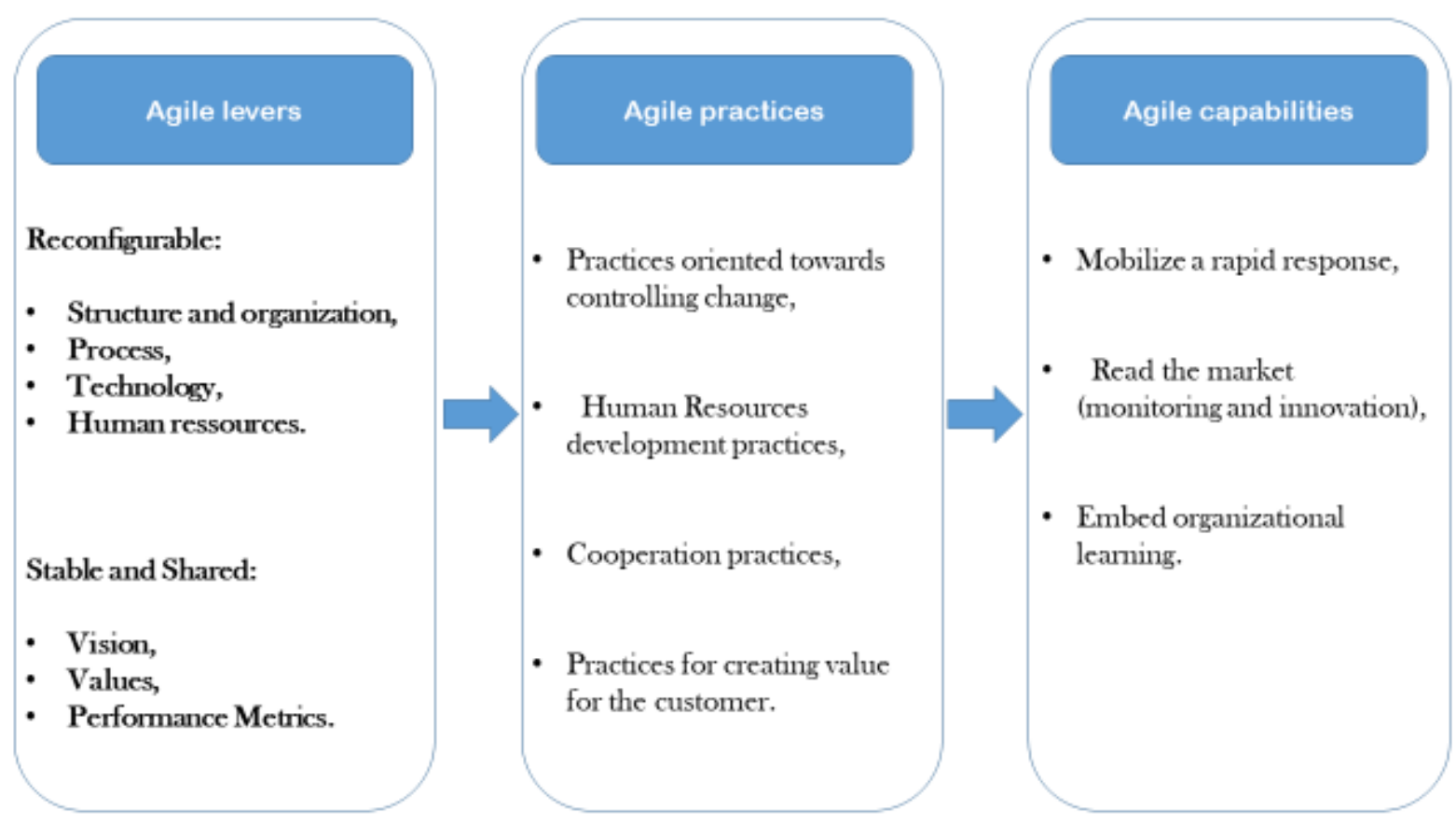

Figure 6: Agile Levers, Agile Practices, Agile Capabilities. (Charbonnier, 2011)

\subsubsection{Enterprise Architecture}

The professional environment is increasingly digital, the Covid pandemic has accelerated the automation of value chains of companies to allow an alternative solution that allows organizations to fulfill their missions and continue to serve its customers in modes of hybrid collaboration or full telework and phygital service or full digital.

To do this, the business model of companies must be reviewed to transform its value architect and align it with the architecture of information systems. The enterprise architecture model known as TOGAF (The Open Group Architecture Framework) allows for a structuring of digital assets according to an urbanization logic (Maxwel, 2017) distinguishing four architectures according to the following hierarchy

- Level 1: Business architecture that represents business objectives and strategy, processes and value chain, and functional aspects.

- Level 2: Data architecture that represents the management of information and related organizational aspects.

- Level 3: Application Architecture represents the software solutions, the software components and the communication mechanisms between these components.

- Level 4: Technical architecture represents the IT infrastructure (hardware) which includes network and telecom systems, hardware and logistics, storage and database management systems and security systems.

The evolution of technological solutions, particularly in terms of multimedia and high-speed telecommunications, large storage capacities at lower server costs, acceleration of processing times for IT solutions, and the evolution of outsourcing expertise are prompting companies to outsource support levels 3 and 4 in order to adopt standard and shared solutions as a service and remain focused on primary levels 1 and 2.

The TOGAF enterprise architecture promotes this distinction and independence between technical platforms. It is guided by application harmony, data quality and service continuity. It adds value at the strategic, organizational and technical levels.

- At the strategic level, it brings more coherence and contributes to the control of complexity and risks. It guarantees the strategic alignment of information systems. Through the digital foundation, it reinforces the reactivity of the company and the acceleration of service time.

- At the organizational level, it contributes to the optimization of resources and the control of information systems. It offers a communication platform between stakeholders and gives meaning to the agile organization of collaborations. It supports internal control and the search for compliance with the company's management standards. 
- At the technical level, it sheds light on the conformity of the IT infrastructure with standards and their evolutions. It enables the interoperability of IT solutions and the enhancement of the company's data capital.

The enterprise architecture, in fine, is inspired by the proven qualities of the business model of digital native companies and becomes an argument for the relevance of the business model transformations of established companies and traditional organizations. It allows to base the value chain and the construction of value on technological advantages. It also allows to serve the sustainable performance of organizations through the gains in effectiveness and efficiency that IT solutions allow. The governance of global performance is then dependent on the governance of the digital asset.

Enterprise architecture enhances agile operation within organizations, supports the culture of collaboration and promotes knowledge sharing and collective intelligence, in order to gain efficient effectiveness.

\subsection{The value of ecosystemic leadership}

1.3.1. Digital transformation of the customer journey and experience

Digital transformation enables primary processes to be optimized, particularly those in charge of marketing, sales and customer relationship management. It brings many benefits to customer service (Julhiet Sterwen, 2018): new business models, new products and customer services, new sales channels and new commitment to customer loyalty.

To foster these contributions, organizations and companies must develop their leadership and digital capabilities.

The leadership capacity is reinforced by the strategic cycles that invite companies to revisit their missions and validate their reasons for being, given the evolution of the environment. It draws its strength from the level of risk appetite and the level of openness to diversity in the corporate culture. It takes its meaning from the level of agility and efficiency of the organization and the quality of execution of strategies.

Digital capability is built through the various digital experiences structured by the enterprise architecture, which ensures that the technological resources mobilized are aligned with the service needs of the organization, the strategy, the governance, the customers and the stakeholders.

The dependent relationship between leadership capability and digital capability is reflected in the influence of one on the other. The objective is to make them evolve towards the best level of maturity to enable the company to become a "Digital Master". This level of maturity is characterized by (Westerman \& Bonnet \& Mcafee, 2016):

- A strong global digital vision making technology trends an inspiration for more innovative ambitions,

- Excellent governance across the silos that organizations can reveal,
- Multiple digital initiatives, through digital projects and digital experiences, enhancing the value proposition of the business model and the profits generated.

- A strong digital culture taking advantage of the attributes and services of new technologies (connectivity, mobility, social media, augmented reality, artificial intelligence and robotics, blockchain, ....) for new managerial practices and new modes of collaboration.

The digital capability translates into the transformation of the company at different levels of management:

- Rethinking according to a disruptive perspective the business model to orient it towards new value propositions that can suggest new strategic business areas,

- Rethink products and services from a "blue ocean" perspective to address new targets representing those "not served" by the available offers,

- Reviewing the product and service offer according to a classic marketing approach in order to make the necessary improvements to retain current customers and to attract customers who are not well served by the competition.

The customer journey is then transformed to embrace omnichannel and phygital approaches and improve service quality. This transformation allows us to rethink customer service. It is an opportunity to :

- Understand customer behavior throughout the customer journey to rethink the customer experience and the internal processes that serve it.

- Mobilize new digital customer relationship channels (mobile applications, social media,) to expand service points and improve customer proximity.

- Track the various interactions and transactions with customers to make the data provided by this customer experience feedback a lever for improving marketing excellence and customer service, on the one hand, and a source of innovation performance and products served, on the other.

- Correlate the digital customer experience with the existing physical experience by integrating digital customer service and relationship points with traditional customer service and relationship points in the customer journey.

Customer journey management becomes an integral part of marketing strategy revisions to reinforce preferred journeys, integrating digital journeys and service points with physical ones in a coherent way. Marketing innovation will de facto concern the innovation of customer journeys and service points.

The goal is to constantly raise the level of customer service excellence and the quality of the customer experience by taking advantage of the six trends in the digitalization of the customer experience (BATAT, 2018): 
- Re-enchant the new consumer according to the values they seek through the purchase of product or service (search for meaning, need for engagement, need for belonging, need for pleasure, ...)

- Capitalize on the customer experience in physical mode to enhance the customer experience in digital mode.

- Integrate in a complementary and coherent way the digital and customer experience and the physical customer experience to enable a global experience (phygital) taking advantage of the technological benefits of customer relations.

- Disrupt the customer approach according to the attributes of the new digital marketing " < blue sunflower marketing " which seeks to amaze the customer to generate the "wow" effect via a surprising, seductive and pleasant customer experience.

- Bring the customer experience to life via "digital storydoing" based on the brand's history, the values to be shared, the customer experience the brand offers, the possibilities of digital tools and channels and the consumption and involvement needs of customers.

- Take advantage of "immersive smart data" technology based on "big data" and artificial intelligence solutions to adopt an in-depth analysis of the experience and better understand the customer profile and personalize the customer experience.

Thus, technology becomes a real argument for marketing disruption and for enhancing the customer experience. The Covid 19 pandemic has corroborated the fallback solutions that digital has offered thanks to digital or phygital paths that have allowed, as much as possible, the continuity of services and the maintenance of customer contact.

Digital customer service solutions allow to reinforce the commercial penetration and extension to serve new products to current customers and to serve current products to new customers.

\subsubsection{Export strategy}

The socio-economic crisis caused by the COVID pandemic has called into question the classic rules of globalization and international trade. This questioning invites a review of the expansion and localization strategies of companies.

These expansion strategies can be based on the following options (Ansoff, 1957)

- Maximize market penetration representing supply and customer base,

- Developing markets by capitalizing on customer relationships to offer new products and services,

- Prospecting new markets and commercial regions to increase commercial transactions for current offerings.

- Disrupt the marketing model to address new markets and business regions with new products and services.

The last two options represent the drivers of internationalization or relocation strategies. They are legitimized by the search for growth levers in promising markets, by the search for risk sharing through local partnerships, by the search for efficiency by taking advantage of economies of scale, and by the search for better productivity by optimizing the use of its resource capacity.

In fact, four factors (YIP, 2003) favor these objectives sought by international strategies: the market, competition, costs and regulation. These factors challenge the four distances, according to the CAGE model ${ }^{1}$, that internationalization strategies must reduce: cultural distance to promote the sharing of values and visions, administrative distance to control procedures and meet compliance requirements, geographic distance to optimize the efficiency of product distribution, and economic distance to align the company's economic model with the determinants of the economic system of the region addressed.

1: Pankaj Ghemawat (management professor of Indian origin) is the author of the CAGE model in 2001.

The internationalization strategies that result from these rules reinforce the physical presence of products and services and consequently take advantage of the expansion effect to increase turnover and consequently revenues.

They are also supported by the digital internationalization strategy, which is informed by the aspects developed earlier: the architecture of the company around digital and the digital enhancement of the customer journey and experience.

\subsubsection{Ecosystems}

The choice of a useful raison d'être and the establishment of an efficient organization to achieve it call for the appropriate mobilization of the necessary skills and resources. This mobilization invites companies to seek out all the internal and external collaborative relationships that can help them counteract the consequences of black swans such as COVID. It invites companies to review their business model in order to open up to their environment and connect to useful ecosystems and build effective collaborative relationships with them.

The notion of ecosystem (Moore, 1996), invited to the field of business, changes the way managers look at their environment in order to perceive the actors who evolve in it and the mechanisms that drive their actions. It proposes three ecosystemic levels:

- "Core business": the heart of the ecosystemic model that includes the basic actors of the value chain: direct suppliers, internal actors and external partners in charge of distribution channels,

- Extended enterprise": the extension of the fields of intervention to suppliers of suppliers, customers, customers of customers and suppliers of complementary products and services.

- Business ecosystem": completes the first two levels to address the control and governance bodies, investors, competitors and other stakeholders impacted by the company's actions (media, NGOs, workers' unions, etc.). 
Ecosystem-based management promotes the development of resilience strategies and their implementation. It allows for the management of the maturation of ecosystems, as shown in the following diagram, according to a renewable cycle that starts from the emergence of ecosystems until their consolidation.

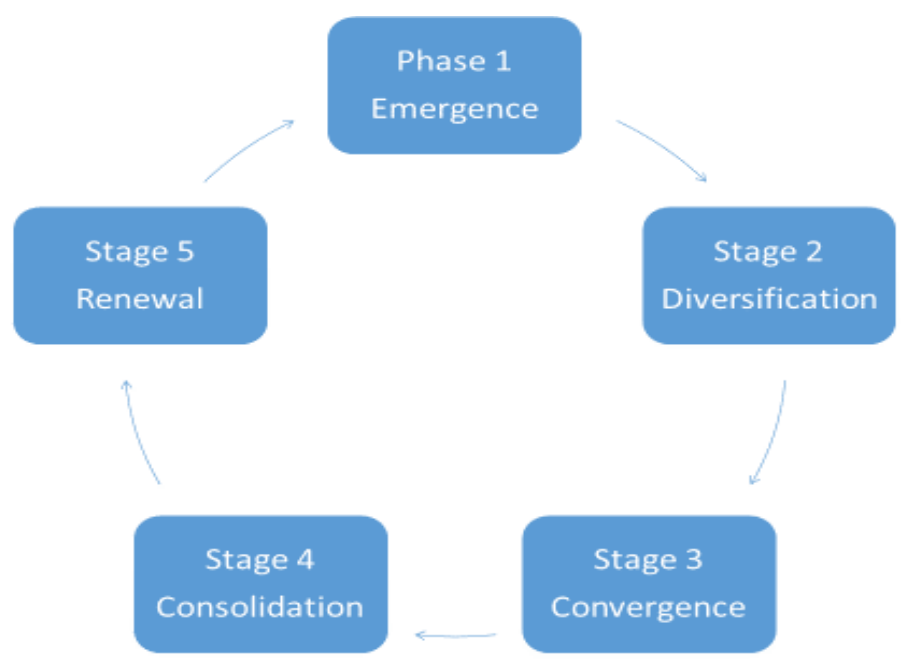

Figure 7: Adapted from the life cycle of a Business Ecosystem (Ka Rong, Yongjiang Shi, 2015).

To drive this cycle, ecosystem management relies on the levers of communication, collaboration and trust (Ben Letaïfa, 2013). Communication allows for information sharing and mutual knowledge building. Collaboration is strengthened by sharing resources and interdependence. Trust is maintained through shared goals and vision and stakeholder engagement.

\section{State of the art}

\subsection{Empirical approach}

As the attached table illustrates, the approach used in all the research studies was qualitative, based on semi-structured interviews with the internal and external stakeholders concerned by the issue. This method of consulting the field allows for constructive exchanges capable of refining the perception of reality and more reliably recording the lived experience. Some research studies have enriched these qualitative interviews with the results of a quantitative evaluation survey.

\begin{tabular}{|c|c|c|}
\hline Objectif & Champ empirique & Acteurs consultés \\
\hline $\begin{array}{l}\text { Strategies at the base } \\
\text { of the economic } \\
\text { pyramid: Cost- } \\
\text { effective approaches } \\
\text { to combating poverty } \\
\text { and social exclusion. }\end{array}$ & $\begin{array}{l}\text { Al Omrane Maroc (Public } \\
\text { organization in charge of the } \\
\text { development of social } \\
\text { housing). } \\
\text { www.alomrane.gov.ma }\end{array}$ & $\begin{array}{l}\text { Semi-structured interviews with representatives of the company and } \\
\text { its ecosystem: } \\
\text { - Al Omrane } \\
\text { - Managing Director } \\
\text { - Organization and Human Capital Director } \\
\text { - } \quad \text { Sechnical and Engineering Director } \\
\text { - Finance and Management Control Director } \\
\text { - Branch Managers (Casablanca, Mohammedia-Benslimane, } \\
\text { - } \quad \text { Head of the Quality and Sustainable Development Division } \\
\text { - Project Managers } \\
\text { - Social Project Management Delegates (M.O.S), in charge of } \\
\text { - Prefectural and Provincial Directors of Housing, Urban Planning and } \\
\text { City Policy } \\
\text { - Prefectural and Provincial Directors of public services for health, } \\
\text { national education, culture and sport, } \\
\text { - Prefectures and Provinces } \\
\text { - Secretaries General }\end{array}$ \\
\hline
\end{tabular}




\begin{tabular}{|c|c|c|}
\hline & & $\begin{array}{l}\text { - Managers of the Town Planning Division } \\
\text { - Presidents of municipal councils (Territorial municipalities) } \\
\text { - Local authorities: Pashas, Caïds and other agents of authority } \\
\text { - Urban agencies: Managers in charge of examining projects } \\
\text { - Private developers: Managers of private developers creating housing } \\
\text { with low total real estate value in partnership with Al Omrane } \\
\text { - Commercial banks: } \\
\text { - Branch Managers } \\
\text { - Individual Customer Advisors } \\
\text { - Service providers: Architects, design offices and construction } \\
\text { companies } \\
\text { - Organizations of } \\
\text { civil society: Members of slum neighborhood associations } \\
\text { Population targeted by slum clearance operations }\end{array}$ \\
\hline $\begin{array}{l}\text { What Intercultural } \\
\text { Management for } \\
\text { multinationals? }\end{array}$ & $\begin{array}{l}\text { Groupe KSB Monde (Une } \\
\text { multinationale allemande } \\
\text { dans le domaine des } \\
\text { pompes) } \\
\text { www.ksb.com }\end{array}$ & $\begin{array}{l}\text { "KSB Voice" satisfaction survey launched by the KSB Group at the } \\
\text { same time: } \\
\text { - } 100 \text { countries } \\
\text { - } 15,645 \text { employees questioned } \\
\text { Semi-structured interviews with representatives of expatriate } \\
\text { managers from the KSB group: } \\
\text { - } 2 \text { subsidiary General Managers (Russia, Spain) } \\
\text { - } 4 \text { Business Unit Manager in Subsidiary (Morocco, Egypt, France, } \\
\text { United Arab Emirates) } \\
\text { - } 4 \text { Division Managers within the Subsidiaries (United Arab Emirates, } \\
\text { Algeria, Equatorial Guinea, Nigeria) } \\
\text { - International Sales Head (Corporate KSB based in Germany) } \\
\text { - Production Manager (South Korea subsidiary) } \\
\text { - Logistic Manager (Canadian subsidiary) } \\
\text { - Program Analytics Lead (Ghana subsidiary) } \\
\text { - Manager (Morocco subsidiary) } \\
\text { - Project manager (Spanish subsidiary) }\end{array}$ \\
\hline $\begin{array}{l}\text { Risk management of } \\
\text { social impact projects }\end{array}$ & $\begin{array}{l}\text { Projets à caractère social au } \\
\text { Maroc financés par la } \\
\text { banque mondiale. } \\
\text { www.banquemondiale.org }\end{array}$ & $\begin{array}{l}\text { Semi-structured interviews with stakeholders involved in the projects: } \\
\text { - World Bank staff } \\
\text { - } \quad \text { Senior Operations Officer-Global Governance Practice } \\
\text { - } \quad \text { Senior Education Specialist } \\
\text { - } \quad 2 \text { Wealth specialist } \\
\text { - Staff Executing Agencies } \\
\text { - Project Director at the Ministry of Health } \\
\text { - Head of the social development department at the Ministry of } \\
\text { - } \quad \text { Manidarity, Social Development, Equality and Family } \\
\text { - Ministry of Economy, Finance and Administrative Reform } \\
\text { - Representative of the Budget Department } \\
\text { - } 2 \text { Manager in the World Bank Unit } \\
\text { - External experts: } 3 \text { consultants } \\
\text { - Ministry of General Affairs and Governance } \\
\text { - Director of International Cooperation } \\
\text { - Senior manager in charge of BM projects } \\
\text { - General Inspectorate of Finance: } 2 \text { Inspector of Finance }\end{array}$ \\
\hline
\end{tabular}




\begin{tabular}{|c|c|c|}
\hline $\begin{array}{l}\text { Neuro-management: } \\
\text { Lever to strengthen } \\
\text { employee } \\
\text { commitment }\end{array}$ & $\begin{array}{l}\text { Direction banque de détail à } \\
\text { la Société Générale Africain } \\
\text { Business Services SGBAS } \\
\text { (Secteur bancaire) } \\
\text { www.societegenerale.africa }\end{array}$ & $\begin{array}{l}\text { Employee survey } \\
\text { - "Retail" department } \\
\text { - } 30 \text { people questioned } \\
\text { Semi-directive interviews with stakeholders SGABS: } \\
\text { - } 3 \text { local managers at SGABS. } \\
\text { - } 1 \text { Production Manager at SGABS. } \\
\text { - } 1 \text { Manager of a support business at SGABS. } \\
\text { - Director of Human Resources at SGABS }\end{array}$ \\
\hline $\begin{array}{l}\text { Collective } \\
\text { intelligence at the } \\
\text { service of business } \\
\text { performance }\end{array}$ & $\begin{array}{l}\text { Mineral Waters of Oulmes } \\
\text { Morocco (An industrial } \\
\text { company in the field of } \\
\text { bottling water and its } \\
\text { marketing) } \\
\text { www.oulmes.ma }\end{array}$ & $\begin{array}{l}\text { Semi-structured interviews with actors concerned at OULMES: } \\
\text { - Director of Human Resources } \\
\text { - Factory manager } \\
\text { - Technical director } \\
\text { - Director of the information systems } \\
\text { - Marketing and Communications Director } \\
\text { - QHSE Director (Quality, Health, Safety, Environment) } \\
\text { - R\&D department managers } \\
\text { - Service managers } \\
\text { - Production team leaders } \\
\text { - Project managers }\end{array}$ \\
\hline $\begin{array}{l}\text { Agility as a lever for } \\
\text { growth }\end{array}$ & $\begin{array}{l}\text { Mining industry of aggregate } \\
\text { production quarries in } \\
\text { Morocco. }\end{array}$ & $\begin{array}{l}\text { Semi-structured interviews with actors representing four types of } \\
\text { companies: } \\
\text { - Subsidiary of a multinational } \\
\text { - Subsidiary of multi-activity Moroccan holding company } \\
\text { - Subsidiary of a large family business } \\
\text { - Main activity of a family structure } \\
\text { - Consultation of } 13 \text { officials: } \\
\text { - } 8 \text { Opairman and CEO and } 5 \text { CEOs } \\
\end{array}$ \\
\hline $\begin{array}{l}\text { Enterprise } \\
\text { architecture and } \\
\text { agility as a strategic } \\
\text { asset }\end{array}$ & $\begin{array}{l}\text { An insurance company in } \\
\text { Morocco. }\end{array}$ & $\begin{array}{l}\text { Semi-structured interviews with stakeholders: } \\
\text { - Director of Information Systems (DSI) } \\
\text { - Deputy Director of Information Systems } \\
\text { - Manager at the DSI } \\
\text { - Project structures: ICT (digital pedagogy), Laboratory (computer } \\
\text { scientists) } \\
\text { - Head of systems and networks department } \\
\text { - Head of management information systems department } \\
\text { - Support department manager }\end{array}$ \\
\hline $\begin{array}{l}\text { Digital } \\
\text { transformation of the } \\
\text { customer journey }\end{array}$ & $\begin{array}{l}\text { Hyundai Maroc (car } \\
\text { dealership) } \\
\text { hyundai.com }\end{array}$ & $\begin{array}{l}\text { Semi-structured interviews with stakeholders at Hyundai Morocco: } \\
\text { - Customer Experience Division (marketing, customer relations, } \\
\text { vehicle purchases) } \\
\text { - After Sales Division (after sales services and spare parts) } \\
\text { - Rabat Branch Director (Commercial Director of the Rabat branch) } \\
\text { - Oujda Branch Director (Commercial Director of the Oujda branch) } \\
\text { - Logistics Division } \\
\text { - Comercial Vehicle development Division } \\
\text { - Finance Division (Administrative and Financial Department) } \\
\text { - IT Division (Information Systems Department) }\end{array}$ \\
\hline
\end{tabular}




\begin{tabular}{|c|c|c|}
\hline $\begin{array}{l}\text { What approach to } \\
\text { improve the customer } \\
\text { experience? }\end{array}$ & $\begin{array}{l}\text { ONCF Morocco } \text { (Public } \\
\text { institution in charge of } \\
\text { managing }\end{array}$ & $\begin{array}{l}\text { Customer survey: } \\
\text { - Random poll } \\
\text { - } 30 \text { answers analyzed } \\
\text { Semi-structured interviews with stakeholders: } \\
\text { - Head of Marketing Department ONCF } \\
\text { - Head of commercial department ONCF } \\
\text { - Head of digital department ONCF }\end{array}$ \\
\hline $\begin{array}{l}\text { What export strategy } \\
\text { for the growth of } \\
\text { SMEs }\end{array}$ & $\begin{array}{l}\text { FIABEL SARL (A } \\
\text { Moroccan SME active in the } \\
\text { field of products and } \\
\text { services related to electricity } \\
(*)\end{array}$ & $\begin{array}{l}\text { Semi-structured interviews with stakeholders: } \\
\text { - General Manager FIABEL* } \\
\text { - Managing Director LFG Engineering* } \\
\text { - Managing Director DISTRIGROUP* } \\
\text { - Export Manager TEMPER* } \\
\text { - ABB Commercial Director* } \\
\text { - Sales Director SCHNEIDER ELECTRIC* } \\
\text { - SOCOOP* Export Manager } \\
\text { - TIMAR* Africa hub coordinator } \\
\text { - TIMAR business manager* } \\
\text { - CENTRELEC logistics manager* }\end{array}$ \\
\hline $\begin{array}{l}\text { What ecosystem for } \\
\text { an effective crisis } \\
\text { resolution regime? }\end{array}$ & Financial sector in Morocco & $\begin{array}{l}\text { Semi-structured interviews with stakeholders: } \\
\text { - Managing Director Bank at Al-Maghrib (Central Bank of Morocco), } \\
\text { - Chief Executive Officer of SGFG } \\
\text { - Director of Macro-prudential Supervision Banque Al-Maghrib } \\
\text { - Director of Social Welfare of the Insurance and Social Welfare } \\
\text { Supervisory Authority (ACAPS) } \\
\text { - Head of Risk Management at the Moroccan Capital Markets } \\
\text { Authority (AMMC) } \\
\text { - Head of the Banking Activity and Financial Stability Division at the } \\
\text { Ministry of Economy and Finance }\end{array}$ \\
\hline
\end{tabular}

The themes challenged by these empirical studies were expressed according to the following questions:

\begin{tabular}{|c|c|}
\hline Thème & Questions de recherche \\
\hline $\begin{array}{l}\text { Strategies at the Base of the } \\
\text { Economic Pyramid: Cost- } \\
\text { Effective Approaches to } \\
\text { Combating Poverty and } \\
\text { Social Exclusion }\end{array}$ & $\begin{array}{l}\text { 1. How to reconcile potentially contradictory logics aimed at simultaneously achieving } \\
\text { profitability and societal value creation objectives? } \\
\text { 2. What position to adopt when focusing on BoP populations? Which segments of poverty to } \\
\text { target? } \\
\text { 3. What reconfiguration of the supply system is necessary? } \\
\text { 4. What role does the partnership between different actors play in the co-creation of inclusive } \\
\text { markets? What impact on operations and on organizational learning? } \\
\text { 5. What are the key strategic skills to maintain, acquire, or develop to succeed in BoP markets? }\end{array}$ \\
\hline $\begin{array}{lr}\text { What } & \text { Intercultural } \\
\text { Management } & \text { for } \\
\text { multinationals? } & \end{array}$ & $\begin{array}{l}\text { 1. The importance of culture as a lever of action for management in a multinational? } \\
\text { 2. At the level of the actors, to what extent does it influence behavior and the possibilities of } \\
\text { responding to given situations? } \\
\text { 3. Are there specific characteristics of the ideal manager who adapts to all multicultural } \\
\text { situations? } \\
\text { 4. And most importantly, how do companies, having succeeded in bringing together national } \\
\text { cultures from all sides, manage to stay on course for growth and competitiveness over time? } \\
\text { 5. Is there a conceptual model of this type of organization that best responds through effective } \\
\text { cultural management? }\end{array}$ \\
\hline $\begin{array}{l}\text { Risk management of social } \\
\text { impact projects }\end{array}$ & $\begin{array}{l}\text { 1. How to effectively deploy Risk Management in a World Bank project? } \\
\text { 2. How is the implementation of a Risk Management System different during the life cycle of the } \\
\text { project, from the preliminary study to the final evaluation? } \\
\text { 3. What tools can we use to assess and monitor risk? } \\
\text { 4. What are the types of risks and what strategies are available to control them? } \\
\text { 5. What is the maturity of Risk Management in Moroccan projects financed by the World Bank? }\end{array}$ \\
\hline
\end{tabular}




\begin{tabular}{|c|c|}
\hline $\begin{array}{l}\text { Neuro-management: Lever } \\
\text { to strengthen employee } \\
\text { commitment }\end{array}$ & $\begin{array}{l}\text { 1. How can scientific research serve the field of management? } \\
\text { 2. How can science help organizations better engage and motivate their people? } \\
\text { 3. What are, according to science, the tools to strengthen this commitment? } \\
\text { 4. Can science help organizations improve their performance? }\end{array}$ \\
\hline $\begin{array}{l}\text { Collective intelligence at } \\
\text { the service of business } \\
\text { performance }\end{array}$ & $\begin{array}{l}\text { 1. How can we concretely and operationally define the concept of collective intelligence? } \\
\text { 2. What are the challenges for collective intelligence? } \\
\text { 3. What are the brakes and the means to free collective intelligence? } \\
\text { 4. What process to bring out collective intelligence? } \\
\text { 5. What management styles to release collective intelligence? }\end{array}$ \\
\hline Agility as a lever for growth & $\begin{array}{l}\text { 1. What are the main techniques, practices and levers related to agility } \\
\text { 2. How to integrate agility into a traditional organization? } \\
\text { 3. How can you take advantage of agility to improve productivity, quality and customer } \\
\text { satisfaction? }\end{array}$ \\
\hline $\begin{array}{l}\text { Enterprise architecture and } \\
\text { agility as a strategic asset }\end{array}$ & $\begin{array}{l}\text { 1. How can we plan the digitalization process and drive business change? } \\
\text { 2. How to set up an agile enterprise architecture? } \\
\text { 3. What are the repercussions of agility on the competitiveness of the company? }\end{array}$ \\
\hline $\begin{array}{l}\text { Digital transformation of } \\
\text { the customer journey }\end{array}$ & $\begin{array}{l}\text { 1. What are the main impacts of digital transformation? } \\
\text { 2. Where is the digital transformation in Morocco? In France ? } \\
\text { 3. What are the prerequisites for achieving this digital transformation? } \\
\text { 4. Where are we? Are we ready to start this digital transformation? What are the main brakes and } \\
\text { obstacles? What are the main customer orientations? } \\
\text { 5. How can we take advantage of digital transformation to get even closer to our customers and } \\
\text { better meet their needs? } \\
\text { 6. Which procedure to follow? What attitude? What are the limits of this transformation? }\end{array}$ \\
\hline $\begin{array}{l}\text { What approach to improve } \\
\text { the customer experience? }\end{array}$ & $\begin{array}{l}\text { 1. How does the end customer want to interact with the brand? } \\
\text { 2. What steps should the company take to improve the customer experience in general and the } \\
\text { digital experience in particular? }\end{array}$ \\
\hline $\begin{array}{l}\text { What export strategy for the } \\
\text { growth of SMEs }\end{array}$ & $\begin{array}{l}\text { 1. What are the strengths and opportunities of the electricity sector that the distributor can exploit } \\
\text { to develop its business? } \\
\text { 2. What are the weaknesses and threats that a company in the sector must face? } \\
\text { 3. What are the development prospects in the Sub-Saharan Africa market? } \\
\text { 4. What are the strategic recommendations to adopt for a successful export experience. }\end{array}$ \\
\hline $\begin{array}{l}\text { What ecosystem for an } \\
\text { effective crisis resolution } \\
\text { regime? }\end{array}$ & $\begin{array}{l}\text { 1. What are the characteristics of financial crises and what are their impacts on performance? } \\
\text { 2. What are the determinants of performance and how to measure it? } \\
\text { 3. What are the prerequisites for a successful crisis resolution regime and how to assess this } \\
\text { performance? } \\
\text { 4. What can be the contributions of management by ecosystem in terms of optimizing the } \\
\text { performance of financial crisis management? }\end{array}$ \\
\hline
\end{tabular}

\subsection{Results of the empirical studies}

The main results of the field investigation are as follows:

- Strategies at the base of the economic pyramid.

The empirical study related to the strategies at the base of the economic pyramid was interested in assessing the openness of business models to the social and societal issues facing companies in these times of crisis and search for meaning. To do so, it assessed the business experience of the case studied through five interdependent criteria: strategic intent, customers and market, supply system, value network and strategic competencies.

The study shows that the alignment of the mission and raison d'être with social and societal issues, especially for a socially oriented organization, backed by a governance system capable of deciding on an inclusive strategic course, gives credibility to managerial action and legitimacy to the actors of the company. It allows the association of economic performance with social and societal performance for a sustainable performance. This translates into a new perception of the people to be served in order to extend the beneficiaries of managerial action to low-income populations and make them a customer segment that can be profitable. This is not without difficulty, as this client segment is heterogeneous and its needs are complex. But this complexity can be a source of innovation and disruption of the value chain to imagine an economically viable product and service offer thanks to a global marketing approach integrating the company's stakeholders and allowing for solutions adapted to the expected uses of the proposed product and service offers. The association of stakeholders concerned by the company's mission and the close management of collaborative 
relationships allows for the sharing of visions, knowledge, resources and work to be accomplished in order to succeed in the challenge of the economic performance of social and societal projects.

\section{- Intercultural Management.}

The new generation of "Covid Era" collaborators is asking for meaning inducers. This meaning is expressed in terms of shared values. As the results of the empirical study on intercultural management illustrate, the top five values found among employees by expatriates are, in order, respect, commitment, team spirit and recognition. These values are the result of professional experience in a context of diversity. These values are not necessarily recognized as compatible with those of the company, since only $53.8 \%$ recognize this compatibility.

Moreover, the mode of collaboration desired by managers favors verbal communication (according to $85 \%$ of those consulted) to facilitate the management of intercultural situations experienced, according to $50 \%$ of the managers consulted, particularly critical situations (according to $75 \%$ of those consulted).

The success of a manager who embraces diversity through expatriation depends more on behavioral skills than on operational skills. Indeed, quality listening (rated 10/10) and recognition (rated 8/10) are widely sought after to the detriment of rigor in execution (rated 5/10),

When a company integrates diversity into its management style, as is the case with multinationals, the integration of personal values with those of the company is facilitated. This is recognized by $70 \%$ of the managers interviewed.

Awareness of the diversity of stakeholders and actors within each stakeholder category in a globalized business world allows the company to align its raison d'être with the imperative of utility that the VICA and post-Covid era has corroborated.

\section{- $\quad$ Risk management.}

The utility imperative is also illustrated by the social projects that the World Bank is supporting in Morocco. Feedback from the empirical study on risk management reveals that despite the strategic alignment of projects with the country's sector strategies, the establishment of processes and quality control, and the adoption of a management style focused on development objectives with performance indicators, improvements are still required in terms of simplifying procedures, motivating and involving staff, and managing risks.

These requirements are justified by the reality of the addressed social environment which highlights a proliferation of poverty, insufficient social coverage and new health risks such as COVID.

\section{- Neuro-management: Lever for strengthening commitment.}

The quest for sustainable commitment recognized by both empirical research and the valorization of purpose is a constant problem for organizations. The feedback from empirical research on the contribution of neuro-management to strengthening commitment corroborates this.

Only $10 \%$ of the employees consulted are satisfied to the point of recommending their companies to their extracorporate entourage. Remuneration is no longer the primary driver of motivation. Instead, employees demand a quality work environment (according to $81 \%$ of respondents) and quality managers (according to $65 \%$ of respondents). Employees are therefore more sensitive to the context in which they carry out their missions. They are also sensitive to recognition practices (according to 58\%) and strategic challenges (according to 52\%).

\begin{tabular}{|l|l|l|}
\hline Furthermore, as the following diagram shows, the & \\
team organization mode brings its added value in & \\
terms of contribution, control of uncertainties and & & \\
efficiency of control processes. & & \\
It gains by taking better advantage of the levels of & & \\
trust within individuals and their predisposition to \\
connect with each other.
\end{tabular}

\section{- Collective intelligence.}

The interconnection of collaborators and their professional collision provides transversality to organizations and favors the construction of experiences and the sharing of knowledge. The imperatives of performance and usefulness in a VICA context require the intelligence of all the internal and external actors associated with the implementation of the mission and strategies.

The feedback from the empirical study in relation to collective intelligence shows the disadvantages of a vertical organization and functioning in silos (according to $100 \%$ of the interviewees). The hierarchical distance alters the 


\section{"Model of Crisis Resilient Organizations"}

recognition of the company's common objectives. $70 \%$ of the interviewees even denounce the absence of common objectives and missions. This may be due to a lack of internal communication, which $85 \%$ of those interviewed consider non-existent or ineffective. This results in a loss of capitalization of know-how which is considered insufficient by $60 \%$ of the interviewees, despite the will to collaborate according to $80 \%$ of the interviewees.

\section{- Agility.}

Collaborative experiences allowing the commitment of employees and the emergence of collective intelligence are favored by the agile management mode. The empirical study related to agility as a growth lever was an opportunity to assess the agile capacity within a sector of activity according to the mode of human capital management, the quality of the digital asset and the operational model in force.

The human capital management mode was assessed according to the practices of skills development, employee autonomy, delegation of responsibility, continuous improvement and creativity. This assessment showed that the human capital component is not sufficiently developed since only $27 \%$ of the companies consulted adopt the practices mentioned. The evaluation of digital assets shows that more than half $(55 \%)$ have invested in digital resources and solutions, particularly in the area of production management and customer relations, but the effective use of these assets shows gaps, since $38 \%$ of the companies consulted are behind in the effective appropriation of technology. The operational model impacted by the quality of human and digital resources mobilized was assessed in terms of internal and external cooperation, proactivity, responsiveness and creation of value for the customer. This assessment reveals that $62 \%$ of the companies consulted have not adopted these agile management principles and suffer from a lack of external cooperation and difficulty in satisfying customers.

The shortcomings cited both at the level of human capital and digital assets as well as at the level of the operational model are more noted in family organizations than in structured organizations (Multinationals, Moroccan Holding). This corroborates the importance of shared values and corporate culture for the adoption of new organizational agility principles.

\section{- $\quad$ Enterprise architecture.}

Digital assets are a lever for agility, and their development depends on the choice of technologies that allow for the best technical convergence with the information system in place, the best functional convergence with the needs of the company's support, primary and management processes, and the best financial convergence for an overall cost of technological management that is compatible with the possible budget.

However, the development of digital assets within companies faces difficulties. The empirical study in relation to enterprise architecture has, in fact, weaknesses in terms of the quality of teams and their ability to work in collaborative and agile mode. It also shows the importance of the resistance to change that any digital transformation project generates. It shows, in fine, the dissatisfaction of the customers.

The challenges of digitalization have become obligations and not choices, since businesses are evolving towards digital versions (e.g.: e-insurance for the case studied) and business practices are evolving towards virtual and remote modes (as observed during the COVID period). The empirical study revealed company assets, through financial health, sales force and quality of work life, and environment attractions, through new expanding markets and competitive lag in adoption of agility practices, to support digital transformation and enterprise architecture projects.

\section{- Digital transformation of the customer journey.}

One of the main objectives of business digitalization and enterprise architecture is the enhancement of the value chain and the business model. This enhancement is expected in the transformation of the customer journey and the enrichment of the customer experience, which is becoming more and more phygital.

The empirical study related to the digital transformation of the customer journey confirms the perception of digital as a lever for efficiency and development according to the unanimous opinion of those consulted. It shows, however, the limit of the means invested to succeed in the digital transformation, according to all the interviewees, the insufficiency of the managerial mode of the digitalization projects as well as the follow-up and coordination, according to all the interviewees, as well as the involvement of the people concerned, according to $80 \%$ of the interviewees. The lack of vision and synergy, according to $30 \%$ of interviewees, and the cultural barrier, according to $86 \%$ of interviewees, aggravate the difficulties of digital projects. However, $86 \%$ of the interviewees recognize the contribution of the digital transformation of the customer journey for the customization of the customer experience and to offer him, according to the "wow" effect, an amazing journey and a unique experience.

This empirical study also revealed that the digital transformation of the customer journey allows to capitalize on the strengths of the brand, the targeting and positioning, the offer and the commercial service to enhance the customer journey and also allows to correct some shortcomings in the supply chain and its efficiency.

\section{- Improved customer experience.}

The empirical study related to the improvement of the customer experience in the rail sector shows that digital initiatives are appreciated by customers. Indeed, more than $76 \%$ are satisfied with the online purchase of tickets through the website or the interactive kiosks. This level of satisfaction is not reached for the physical service points since $57 \%$ of the people consulted are not satisfied with the quality of travel on board trains and $83 \%$ are dissatisfied with the quality of the information shared via the physical channels. According to 
$54 \%$ of those interviewed, an effort still needs to be made to improve the commercial information shared online or via mobile solutions.

The study highlights the contribution of digital channels to improve customer relations and enhance the service experience. Digital channels allow to correct the cognitive gap, to compensate the insufficiencies of physical customer relationship and service channels and to highlight the company's reputation and the advantages of its products and services. They also allow to extend the customer relationship beyond the physical points of service and to appeal to a large audience in order to attract more customers and generate more commercial transactions.

\section{- Export Strategy for Growth}

Attracting more customers and more business transactions is a growth objective for all companies. Expanding the target customer base to new markets is one way to achieve this.

The empirical study in relation to the export strategy for growth has highlighted the strengths that can be capitalized and the opportunities that can be seized to foster growth through exporting. Indeed, the company can build on resources reinforced by feedback in terms of physical resources and infrastructure, in terms of human resources and production and marketing know-how, in terms of image and customer network and in terms of digital assets. It can take advantage of the business opportunities proposed by the African markets, the expectations of these markets in terms of compensating for the absence of service or competing with the existing offers to improve the services provided. It can also take advantage of the cultural, administrative, geographic and economic proximity with the target African countries.

The empirical study also highlighted the obstacles to the success of an export strategy. These include weaknesses in the organization and internal communication processes and in the customer relationship management process (segmentation, customer risk assessment, sales promotion and customer debt collection). It is also about the constraints of the environment in terms of Turkish and Chinese competition, in terms of regulations and normative rules, and in terms of social and societal constraints especially because of pandemics such as Covid which alter the propensity of globalization and encourage the relocation of business.

\section{- The ecosystem for an efficient crisis resolution regime}

Openness to its environment can be a source of effective and efficient resolution of business problems, especially when these problems can have a negative impact not only on the company but also on its stakeholders and ecosystems.

The empirical study in relation to a successful ecosystembased crisis resolution regime has shown that crises are systemic, involve other types of crises and are the result of the cumulative difficulties of several economic agents. The culmination of this accumulation over time and the densification of the difficulties of the different actors translate the crises and determine their acuity. This study also shows that the sharing of problems and crises by actors in an ecosystem can result in the sharing of a vision, objectives and resources to build effective and efficient solutions that serve the performance of all stakeholders.

The study also shows that poor organization and coordination of the ecosystem, characterized by diluted responsibilities, unclear roles and boundaries, and weak evaluation, monitoring, and regulatory mechanisms, undermines the collaboration of ecosystem stakeholders and does not take advantage of the internal capacities of the actors involved.

\section{Discussion of the results}

\subsection{The value of purpose}

The research findings shed light on how to read the resilience requirements of organizations in a VICA (Volatile, Uncertain, Complex, Ambiguous) context and black swans such as COVID.

The study in relation to BOP strategies shows that the social and societal imperative that is imposed on today's strategies can be an invitation to embrace new managerial thinking that makes it a source of transformation of organizations and value chains to develop and carry out innovative strategic models capable of combining economic performance with social and societal performance. Such models address the unserved or underserved spaces that can mobilize the right partners and build a de facto ecosystem committed to a culture of shared goals, resources, risks and performance.

This commitment can only be effective if the actors involved align their raison d'être with a vision of sustainable development. This responsible commitment allows for the improvement of the portfolio of products and services delivered and its integration to align the benefits provided by the products and services delivered with the specific needs of the population addressed.

The success of this kind of bold strategy is aided by an awareness of the cultural diversity of the stakeholders representing the company's ecosystems. Cultural diversity enriches strategic thinking and organizational performance.

Indeed, as the study on intercultural management and multinational experiences has shown, cultural dimensions influence the perception of space, time and interpersonal relationships. Awareness of the specific values of each actor in the ecosystems allows for the construction of a value base that allows for the understanding of the values of all actors and de facto recognition of shared values that can support a shared vision and foster collaborative commitment.

The cultural repository explored in this way supports the management style of collaborative relationships and the facilitation of organizations set up to undertake joint projects. It brings out the behavioral qualities sought by employees, particularly in times of crisis, namely listening, recognition, rigor and compassion, in order to encourage their commitment with professionalism and team spirit. 


\section{"Model of Crisis Resilient Organizations"}

This reference system will ultimately enable us to refine the application of the revised raison d'être so that it remains a constant source of inspiration for proactive and pro-active strategies, and to shed light on the process of implementing these strategies while controlling the risks of underperformance.

The study in relation to risk management has shown that social and societal missions must meet the challenge of dealing with the VICA expression of the fields of action, particularly in terms of the complexity of the environment addressed.

Risk management then becomes a skill required by an official and exhaustive model that structures internal control and performance management. This kind of model frames risk management at all managerial levels of the company: legal compliance, project risk management and risk taking in the business models and strategies developed.

Risk management, intercultural management and base-ofthe-pyramid strategies can then give meaning to the revision of the company's raison d'être and validate its alignment with social and societal imperatives and the challenges of sustainable development, and ultimately generate the commitment of internal and external actors.

\subsection{The importance of organizational efficiency}

Commitment is one of the levers of organizational excellence. As the study on neuro-engagement as a lever of commitment shows, commitment is a complex concept that can benefit from the knowledge of neuro-management and the study of the human brain to understand the behavior and functioning of individuals. This understanding makes it possible to become aware of the emotional context that accompanies human relationships and also to understand the behavior of individuals in order to better manage teams and collective actions. The study shows that a culture of trust and transparent organizational dialogue promotes commitment. It also shows that a learning culture that takes into account the connection of collaborators, the right to make mistakes and self-management reinforces this commitment. It also shows that an evaluation and motivation process based on justice, social recognition, consideration of personal projects and self-compassion maintains this commitment.

The commitment of the collaborators optimizes the plural efforts and the use of shared resources and consequently favors the efficient effectiveness of collective experiences. Capitalizing on collective experiences enriches the knowledge capital of the actors and promotes the collective intelligence of the teams. This collective intelligence, as shown in the study on collective intelligence as a lever for business performance, strengthens the analytical skills of managers and their ability to manage complexity in order to improve performance.

To establish this collective intelligence, organizations must energize the communication process and enhance its mechanisms. They must develop the ability to listen to stakeholders in order to fuel the learning and innovation processes. The practices of listening, communication and sharing are best articulated around a shared vision, innovative products, permanent customer service channels, a digitalized value chain, a customer-oriented trans-versal operation and organizational efficiency.

Organizational efficiency in a volatile and stochastic context, as shown in the study related to agility as a growth lever, requires the liberation from bureaucratic organizational models driven by control and the search for reliability to move towards agile models favoring collaboration, empowerment and adaptation. This study has also shown that the culture of agility that has emerged in the IT and soft process businesses can be of interest to other businesses and enable them to make their hard processes more flexible. This culture takes advantage of the commitment of employees, the sharing of learning and innovation experiences and the collective intelligence that results from this to direct resources and efforts towards growth and progress. They mobilize front-office teams in charge of customer experience, backoffice teams in charge of business processes and those in charge of technological systems and resources through agile levers to drive the value chain.

These agile levers, linked to flexible organizational structures, talented human resources, continuously improving processes and value-added technological resources, contribute to the creation of value for customers, the satisfaction of governance expectations and the development of performance for other stakeholders.

The culture of agility brings management closer to technology and reveals organizational capabilities to succeed in digital transformations of processes, value chain and business model.

As the study shows in relation to enterprise architecture and agility as a strategic asset, the development of digital capabilities of organizations requires the strategic alignment of information systems, through an enterprise infrastructure approach, and the synergy of stakeholders in digitalization projects and information systems management, through an agile collaboration style. The study showed that these two levers, "enterprise infrastructure" and "agility", can structure the development and deployment of digital transformation projects, contribute to the management of change, and enable a gain in effectiveness and efficiency of the solutions implemented.

Enterprise architecture is also an opportunity to arbitrate the adoption of technological solutions that are compatible with confirmed trends. These trends are expressed in terms of technology as a service and free the company from investing in proprietary IT infrastructures that require technical expertise to manage them. This is made possible by technological innovations in broadband telecommunications, smart phones and mobile solutions, data centers and cloud computing, software packages and web solutions and artificial intelligence and data science. 


\section{"Model of Crisis Resilient Organizations"}

\subsection{The Value of Ecosystem Leadership}

The above-mentioned proven technological advances, as shown in the study related to the digital transformation of the customer journey, enable an improvement of the customer journey and support the omni-channel sales approach and a phygital service mode that combines the digital channel with the physical and contact channel.

This transformation of the customer journey requires a digital upgrade of the company's processes and the journeys of other stakeholders (suppliers, collaborators, partners, distributors, etc.). All ecosystems must be digitally integrated so that technological solutions can support the value chain and be a collaboration tool to better serve the customer.

A $306^{\circ}$ approach is then indicated to accompany the customer throughout his journey from the expression of needs to final satisfaction. The management of the customer relationship allows to adapt at each step of the journey the physical or digital solution to the customer service mode. The feedback of this customer relationship and the feedback of the commercial performance monitoring and the level of excellence in customer service inform the appropriate technological choices (Customer Relationship Management Solutions, commercial platforms, web solutions, mobile solutions, artificial intelligence solutions, etc.).

The contribution of digital to enhance the customer journey and enrich the customer experience has also been confirmed by the study in relation to customer improvement. This study reaffirms the importance of digital alignment of back-office processes, both primary and support processes, with the expected digital enhancement of the customer experience. This study also shows that this alignment can lead to the diversification of strategic business areas, product lines and services. It is also an opportunity to fully exploit the digital capacity of the organization and the capacity of other resources to translate them into added value in the product offering and customer service. The study shows that this alignment is best achieved through collaboration with the stakeholders in the ecosystem.

Managing the performance of the customer journey and the customer experience enhances ecosystem leadership by exploring the right stakeholders and building collaborative relationships that generate progress.

The search for levers of progress, as shown in the study in relation to the export strategy as a growth lever, can invite companies that have proven themselves in local markets to address foreign markets according to an export strategy that can develop a commercial performance hampered by the competitive intensity or saturation of the local market. The use of export allows the company to take advantage of opportunities in foreign markets and to replicate successful business experiences in a local market in other markets.

The study shows that the development of an export strategy can be accompanied by a diversification of strategic activities to allow products and services with added value for new customer segments. The deployment of the export strategy can take advantage of partners in the targeted regions to strengthen the company's ecosystem with new stakeholders and better serve the new customer ecosystems.

Thanks to the new partner ecosystem, the company can succeed in its commercial action in an efficient way by taking advantage of the resources, the territorial knowledge and the experience of the partners to set up an optimal logistic chain. The company's ecosystems are enriched by the collaborative and transactional opportunities that export strategies allow. Ecosystemic management is now taking a strategic place in the managerial model of companies, especially in a VICA environment and in crisis situations.

Indeed, as shown in the study related to the ecosystem as a support for an efficient crisis resolution regime, ecosystemic collaborations allow to avoid the negative impacts of systemic crises such as financial and health crises. Resolving systemic crises requires the coordinated involvement of multiple stakeholders and collaboration driven by rules for sharing knowledge, resources, effort, and performance.

To contain the multiple legal/political, socio-economic, technological and ecological risks that a company may face, it needs the support of all internal and external stakeholders in its ecosystems, both nationally and internationally.

Ecosystem leadership allows the company to be in a prime position to lead collaborative relationships. It can be legitimized by legislation or by a formal designation as a crisis resolution authority. It is more appreciated when it emanates from managerial courage and strategic initiative to assert the company's leadership capacity in its sector of activity or region of evolution.

The contribution of ecosystemic leadership to resolving crisis situations is effective if the powers of resolution are well assigned, if the instruments of resolution are mobilized and if the coordination mechanisms are adapted to the requirements of agile collaboration.

\subsection{Resilient organization model}

The model of resilient organizations that can be derived from the results of the research deciphered in this article is the result of an interconnection of several managerial fields in order to identify the organizational complexity that is called upon to operate at the limit of chaos. It can be broken down into three interdependent layers as shown in the following diagram: 

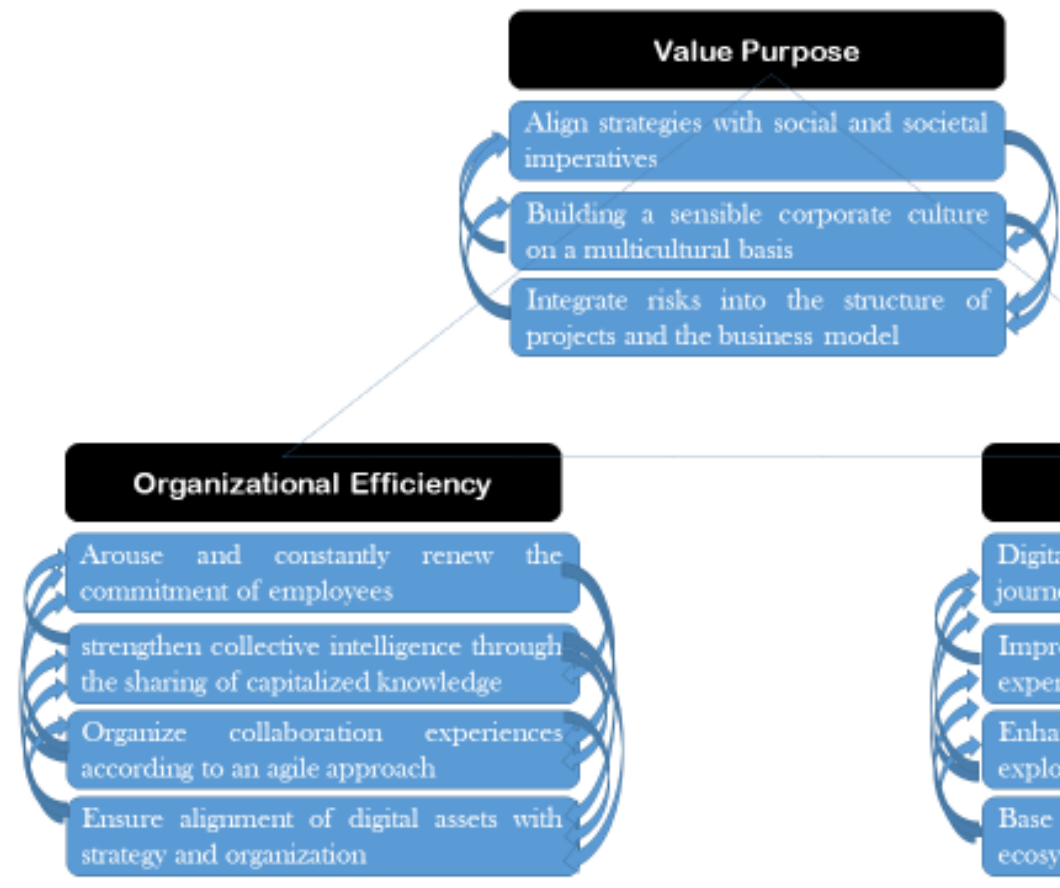

\section{Ecosystem Leadership}

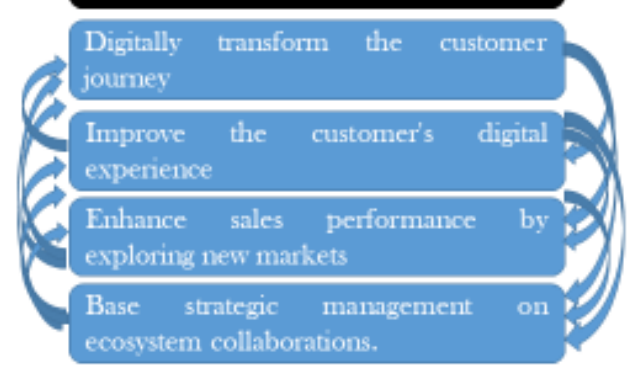

Figure 9: Resilient Organizations Model (Source: Author)

\section{- Valuing purpose}

Companies in the era of pandemics and systemic crises, such as Covid, "benefit from perceiving the VICA signals from the environment as an invitation to revisit their missions and visions in order to find connections with these signals that will enhance their raison d'être and align their actions with the structural demands of the environment. This valorization can be based on three interdependent options whose relevance has been verified in the research presented in this article, namely

- An intelligent alignment of strategies with social and societal imperatives to transform social and societal problems and frustrations into business opportunities and stakeholder engagement ignored by traditional strategic models.

- A cultural foundation of the business model and the managerial model enriched by the openness and capture of cultural diversities to embrace the complex reality of the profiles of the actors with whom companies will be called to interact, especially in a context of business globalization.

- An enlightened risk management that perceives threats and changes in the environment as surprises that can suggest opportunities to optimize projects and business models.

\section{- Organizational efficiency.}

Economic performance is more about optimizing expenses and eliminating waste than it is about growing revenues, which are limited by competition and market saturation. This efficiency can result from a management style that draws its strength from four interdependent options

- The commitment of the collaborators generated by a culture of trust that frees the organization and energies and gives the human intelligence a space for expression and learning. This commitment provides each employee with the responsibility and autonomy to do more and better with fewer resources, thereby enabling the company to be more frugal.

- Collective intelligence driven by a knowledge management strategy that recognizes tacit and explicit knowledge capitalized on feedback and shares it to generate value. Collective intelligence improves the organization's understanding of intramural events and environmental levers and promotes better reactivity, but also better proactivity.

- Organizational agility, which encourages the organization of work in teams and, whenever possible, in project mode. It allows actors to collaborate around shared objectives and customer service, and takes advantage of the continuous improvement process and the learning culture. It allows, therefore, to reduce the efforts and the use of resources to allow viable and efficient solutions.

- Enterprise architecture, which allows the business model architecture and the value chain to be based on the technological resources mobilized by the company. It enables the successful integration of technology with the company's business and management processes. This integration takes advantage of the technological benefits for an efficient organization.

- Ecosystemic leadership.

The complexity of the environment invites the company to develop more proximity with its action space in order to measure the impacts that the management of its activities produce. The knowledge of the actors impacting the performance of the company or impacted by its action allows 


\section{"Model of Crisis Resilient Organizations"}

defining the scope of actors with whom it is appropriate to interact to share risks, resources, collaborations and performance. Ecosystemic leadership is a skill that the company can develop through four options:

- The digital transformation of the customer journey that allows the integration of all service channels that challenge the presence of the customer. It allows the company to understand the extent of customer ecosystems and the multiplicity of contact points. It also allows us to identify possible intermediaries to better serve the customer and thus enrich the ecosystem of partners.

- Improving the customer experience through digitalization, which can be the result of effective customer relationship management. This enables the development of customer affinity and the personalization of offers in order to move towards excellence in customer service. Excellence in customer service requires mastering the emotional forces that drive the act of purchasing and also the advantages provided by the products and services sold, which bring added value to the customer.

- Growth via an export strategy that allows the company to prospect for promising markets in new economic areas to promote the quality of its products and services and thus expand its commercial sphere and its customer and partner ecosystems.

- Ecosystem-based management, which can steer the strategies developed and promote their proper deployment. It allows the company to become aware of all the players involved in the company's mission. This knowledge allows us to appreciate the dependencies between the actions of the different actors and to locate the fields of collaboration to be developed and promoted. It allows, in fine, to gain in frugality and resilience.

\section{CONCLUSION}

The results of this meta-research, which takes advantage of the results of a dozen or so research projects conducted in the context of covid, have made it possible to question current management doctrines in order to find an answer to the determinants of the resilience sought by individuals, companies, nations and the entire world.

The compilation of the results of this research, which was conducted and concluded in 2020 with a focus on the issue of resilience, has led to the emergence of a model of efficient organizations. This model has been proposed to the organizations I work with in my professional sphere to test it. The principles they propose have inspired the managers of these organizations to integrate them into their managerial model.

Moreover, this moment of questioning is also a moment of awareness of the transformation of managerial models and the disruption of their rules. This managerial disruption can be elucidated by the following enumerations:

- The environment can no longer be perceived only as threats and opportunities with a focus on the meso- and micro-environment but must also be appreciated according to a macro-environment and in VICA (Volatility, Uncertainty, Complexity and Ambiguity) to identify the climatic and sustainable development issues that will drive social and societal imperatives.

- VICA management will require a holistic, euristic and skeptical management style to deal with the complexity and stochastic variables of the environment and to be prepared to identify the weak signals of this global environment and the black swans that may result from it.

- The strategic advantage is no longer based on the focus on core business but on the focus on core competencies as the waves of disruption are accelerating and challenging the businesses of established companies. Only the skills capitalized by the feedback can count to rethink the business, the products and services.

- Traditional strategic management is being replaced by strategic thinking and Now strategy, which encourages managers to integrate all stakeholders in any decisionmaking process. This enables the development of an open strategy capable of scrutinizing the environment and detecting unexplored service areas (blue ocean approach).

- The adoption of outsourcing is a management principle to outsource not only support activities but also critical activities when this allows to gain in performance and risk sharing.

- The integration of a risk-taking culture to improve risk appetite among employees and managers so that risk management finds its place in the search for performance at the project and business model levels.

- The design of a global performance model (ESGW) that goes beyond economic performance objectives (E) to integrate social performance $(S)$, good governance $(G)$ and employee well-being (W).

- Organizational leadership processes are now based on a culture of multicultural trust, teamwork and adaptability, rather than on traditional principles of hierarchy, silo management and reliability control.

- Change is no longer integrated as a project to be managed or driven, but as a management style that favors agility and the constant transformation of processes.

- The notion of the customer that classical marketing has promoted is extended to include all the stakeholders in the company's ecosystems as beneficiaries of the company's actions. This approach makes it possible to negotiate the balance of interests of the actions concerned by the company's mission. 
- The managerial transformations that digital business experiences have revealed are adopted to approach the value chain and business mo-del of native-digital companies and unicorns models.

- $\quad$ - The management of employees and human resources is supplanted by talent management and COBOT management (Collaborators and Rebots) to successfully integrate the intelligence of talents and the intelligence of technologies and artificial intelligence.

- $\quad$ - The organization and working time is now hybrid where telecommuting is becoming an inevitable mode to manage the employee relationship and his or her engagement in these times of mobility and crisis. This generates a transformation of the flexible and shareable working offices, transforms the employee's career path and calls for an integration of private life with professional life rather than managing, as before, their balance.

- $\quad$ - The collaborator is no longer seen as an employee and an expense center but as a partner who builds his job (job-crafting) and acts as an entrepreneur to give meaning to his contribution.

All of these enumerations are already observed at the level of leading companies in various sectors of activity, especially those based on a digital culture, and are shared by several centers of expertise and think-tanks.

These enumerations do not claim to be exhaustive, but they question the reality of companies today and also the training programs within universities and business schools and the research laboratories in management sciences.

\section{BIBLIOGRAPHY}

1. Ansoff E. (1957), Diversification strategies, Harvard Business Review.

2. Aini Y. (2020), L'intelligence collective au service de la performance des entre-prises. Cas des Eaux Minérales d'Oulmès, Professional thesis directed by Dr CHAGAR H. in the framework of the AMBA accredited Executive MBA, ISCAE Group.

3. Anderson, J., and N. Billou (2007), Serving the world's poor: innovation at the base of the economic pyramid, Journal of Business Strategy.

4. Bahsani S. (2020), Enterprise architecture and agility as a strategic business asset. Cas d'une compagnie d'assurance en période de crise sanitaire COVID 19, Professional thesis directed by Dr. CHAGAR H. in the framework of the AMBA accredited Executive MBA, ISCAE Group.

5. Benmekki M. (2020), Risk Management in the World Bank's projects: proposal of a conceptual framework, Professional thesis directed by Dr. CHAGAR H. in the framework of the AMBA accredited Executive MBA, ISCAE Group.

6. Bennis Y. (2020), Transformation digitale du parcours client: Cas de Hyundai Maroc, Professional thesis directed by Dr CHAGAR H. in the framework of the AMBA accredited Executive MBA, ISCAE Group.

7. Benzouina A. (2020), Which approach to improve the customer experience? " Cas de l'ONCF ", Professional thesis directed by $\mathrm{Dr}$ CHAGAR $\mathrm{H}$. within the framework of the AMBA accredited Executive MBA, ISCAE Group.

8. Berry et al (1992), The relationship between acculturation attitudes and behavioral changes.

9. Boulmane I. (2020), Which ecosystem for an efficient financial crisis resolution regime in Morocco, Professional thesis directed by Dr. CHAGAR $H$. in the framework of the AMBA accredited Executive MBA, ISCAE Group.

10. Camilleri C. (2016), in Acculturation and interculturality, (https://ancrages.org/wp-content/ uploads/2016/11/Acculturation-Interculturalite.pdf

11. Carmen M. Reinhart and Kenneth S. Rogoff (2009), this time is different: a panoramic view of eight centuries of financial crises, Princeton university press.

12. Charbonnier A. (2011), Characteristic model of organizational agility.

13. Darrell K. Rigby, Jeff Sutherland, Andy Noble (2018), Agile at Scale, Harvard Business Review May June 2018.

14. El fechtali Y. (2020), Agility as a growth lever in the Quarry Mining Aggregates Production industry, Professional thesis directed by Dr. CHAGAR H. as part of the AMBA accredited Executive MBA, ISCAE Group.

15. Ennajar N. (2020), Neuro-management: Lever for strengthening employee engagement, Professional thesis directed by Dr. CHAGAR H. as part of the AMBA accredited Executive MBA, ISCAE Group.

16. Gephardt \& Van Buren (1996), The power of highperformance work systems. Training and development.

17. Gerry Johnson, Richard Whittington, Kevan Scholes, Duncan Angwin And Pat-rick Regnér (2017), exploring strategy,

18. Gollakota, K., Gupta, and J. T. Bork (2010), Reaching customers at the base of the pyramid-a twostage business strategy, Thunderbird International Business Re-view. J.ZAK, P. (2017), Trust Factors The science of creating high-Performance companies , New York: AMACOM.

19. Hopkinson Martin (2011), The Project Risk Maturity Model: Measuring and Improving Risk Management, Gower publishing.

20. Ka Rong, Yongjiang Shi (2015),business ecosystems, constructs, configuration and the nurturing process, Palgrave Macmilan, p.215 
21. Kahneman D. (2012), System 1 / System 2: The two speeds of thought.

22. Lehmann-Ortega Laurence, Leroy Frederic, Bernard Garrette, Pierre Dussauge, Rodolphe Durand (2016), STRATEGOR, 7th Edition, 2016.

23. Lévy P. (1997), L'intelligence collective : pour une anthropologie du cyberspace, la découverte.

24. Luc Laeven and Fabian Valencia (2013), systemic banking crisis database, Inter-national Monetary Fund Working paper

25. Luc Laeven and Fabian Valencia (2018), systemic banking crisis revisited, Inter-national Monetary Fund Working paper

26. Martinet, A. C., and M. A. Payaud (2010), La stratégie BoP à l'épreuve des pauvretés : une modélisation dialogique, Revue française de gestion, $\mathrm{n}^{\circ}$ Spécial "Entreprise et Pauvreté", vol. 36, n²08209.

27. Maxwel, R. (2017), TOGAF (The Open Group Achitecture Framework),

28. McKinsey\&Compagny (2015). The agile mine is built on four ma-jeur pillars:

29. Mellouk Y. (2020), Which intercultural management for multinationals: Case KSB World Group Professional thesis directed by Dr. CHAGAR H. in the framework of the AMBA accredited Executive MBA, ISCAE Group.

30. Merras H. (2020), Les stratégies à la base de la pyramide économique : approches rentables pour lutter contre l'exclusion sociale. Cas du Groupe Al Omrane, Professional thesis directed by $\mathrm{Dr}$ CHAGAR H. within the framework of the AMBA accredited Executive MBA, ISCAE Group.

31. Moussali Z. (2020), What export strategy for the growth of Moroccan SMEs? Cas de FIABEL SARL", Professional thesis directed by Dr. CHAGAR H. in the framework of the AMBA accredited Executive MBA, ISCAE Group.

32. Moore James F. (1996), business ecosystem.

33. Moore James. F (1996), The Death of Competition: Leadership and Strategy in the Age of Business Ecosystems, John Wiley \& Sons.

34. Perrot F. (2011), Multinational Corporations at The Base of The Economic Pyra-mid: A Strategic Analysis Framework, Ecole Polytechnique ParisTech.

35. PwC (2017), Global Digital Study.

36. Rock D. (2008), SCARF : A brain-based Model for Collaborating With an Influ-ence Others " , NeuroLeadership Institute

37. Shafer R.A. (1997), Creating organizational agility. The human resource dimension. Unpublished Ph. D dissertation, Cornell University.

38. Schrader, C., J. Freimann, and S. Seuring (2012), Business Strategy at the Base of the Pyramid,
Business Strategy \& the Environment (John Wiley \& Sons, Inc).

39. Soumaya Ben Letaïfa (2013), A methodology for ecoystem creation: how organizations can shift from supply chains to ecosystems, in "understanding business ecosystems", ed de boek.

40. Sterwen Julhiet (2018), Barometre J\&S

41. Stijn Claessens and M. Ayhan Kose (2013), Financial Crises: Explanations, Types, and Implications, january, International Monetary Fund Working Paper, Research Department.

42. Trompenaars Fons \& Hampden-Turner Charles (2010), L'entreprise multiculturelle, Publisher: Maxima Laurent du Mesnil, France.

43. Westerman George, McAfee Andrew and Bonnet Didier (2016), Leading Digital: Turning Technology into Business Transformation, Diateno.

44. Wided BATAT (2018), Designing and improving the digital customer experience.

45. YIP (2003), Total global Strategy.

46. Zaïbet, Greselle (2007), Towards the collective intelligence of work teams: a case study, Management \& Avenir.

47. Zak Paul J. (2017), Trust Factors - The science of creating high-Performance companies, New York: AMACOM.

48. ZARA O. (2016), Managing collective intelligence towards a new organization. 